\title{
Photographs from the Grahamstown Lunatic Asylum, South Africa, 1890-1907
}

\author{
Rory du Plessis \\ Department of Visual Arts, University of Pretoria, Pretoria, South Africa \\ Department of Visual Arts, University of Pretoria, Private Bag x 20, Hatfield, 0028 \\ Email: rory.duplessis@up.ac.za \\ Rory is a lecturer in Visual Culture Studies in the Department of Visual Arts, University of Pretoria
}

This essay investigates photographs taken at the Grahamstown Lunatic Asylum during the superintendency of Dr Thomas Duncan Greenlees, 1890 to 1907. It examines two specific sets of photographs: first, the photographs taken for public consumption, and, second, the casebook photographs of the patients. I argue that the photographs produced for public consumption ascribe to the broader public image of the asylum. Greenlees constructed a public image of the asylum being committed to the curative regime of moral therapy while catering to the tastes, proclivities and activities of white private patients. The photographs for public consumption also include images of black patients. Yet, there was differential treatment for black patients. Under Greenlees' superintendency they were assigned supervised physical labour tasks under the pretext of them being occupational treatment. The discourses of cure and recovery in such a 'treatment' regimen become signalled by the black patient's ability to work. Thus, the curative ideal of the asylum for black patients, disseminated as its public image, is primarily concerned with domesticating black bodies into a docile and cooperative labour force. However, the public image of black patients as being passive before the asylum's regimen is problematised through an analysis of the second set of images - the casebook photographs. These photographs depict patients confronting, refusing and resisting the asylum administration. Thus, the casebook photographs are valuable in recuperating active resistance and hold the potential to undermine the public image of the asylum.

Keywords: casebook photographs; colonialism; Grahamstown Lunatic Asylum; Thomas Duncan Greenlees; lunatic asylums; moral therapy; photography 


\section{Introduction}

This essay investigates photographs taken at the Grahamstown Lunatic Asylum during the superintendency of Dr Thomas Duncan Greenlees, 1890 to $1907 .{ }^{1}$ It examines two specific sets of photographs: first, the photographs taken for public consumption, and, second, the casebook photographs of the patients. ${ }^{2}$ I argue that the photographs produced for public consumption ascribe to the public image of the asylum. Greenlees constructed a public image of the asylum being committed to the curative regimen of moral therapy while catering to the tastes, proclivities and activities of private patients. This public image was propagated and promoted through photographs to the wider public. Accordingly, for Greenlees, photography performed a crucial role in constructing a restorative and recuperative image of the asylum which was to appeal to and persuade the public of the asylum's suitability for taking care of private patients.

The photographs for public consumption include images of both white and black patients. Greenlees' superintendency was characterised by the differential treatment of black patients. They were assigned occupational activities which provided an unpaid labour force for the running of the asylum. The discourses of cure and recovery in such a 'treatment' regimen were signalled by the black patient's ability to work. Thus, the curative ideal of the asylum for black patients, disseminated as its public image, was primarily concerned with domesticating black bodies into a docile and cooperative labour force. Yet, the public image of black patients as passive before the asylum's regimen is problematised by the second set of photographs - the casebook photographs. These photographs depict patients confronting, refusing and resisting the asylum. Thus, the casebook photographs are valuable in capturing active resistance and hold the potential to undermine the public image of the asylum.

In relation to both sets of photographs, I aim to “... examine the potential of the simultaneous, multiple and often contradictory meanings inherent in images of 
madness" (Gilman 1996, 225). In view of this, the essay is a reading of how photographs can be subjected to different perspectives thereby exposing potentially new meanings and, in this case, provide representations of patients demonstrating “... a multiplicity of points of resistance" (Foucault 1979, 95) as a response to the asylum's regimen. The casebook photographs counter the myth of patient docility and passivity and act as an unofficial record of patients refusing the clinical gaze, patients expressing disdain for the institution and of exhibiting a plurality of resistances.

\section{Background}

In the first decades of the nineteenth century, the Western world shared a belief in moral therapy's postulation that residing in a specifically designed setting of the asylum offered a potential cure to madness (Parle 2007, 50). ${ }^{3}$ The central tenets of moral therapy practised at asylums hinged on two factors: the removal or abolition of all forms of physical punishment and restraint; and the provision of a regular routine of leisure activities and useful means of occupation conducted in the restful and aesthetically pleasing environment of the asylum (Sachs 1999, 239). Moral therapy thus offered an alternative to prior established approaches to 'treatment' that consisted of incarcerating the mentally ill in huge state institutions that resembled prisons (Curtis 2004, 197). In these institutions, the conditions were particularly poor and the treatment included chaining the mentally ill to the walls, or keeping them in cages or holes in the ground (Curtis 2004, 197; Yanni 2003, 25). Not only did moral therapy provide improvements in the treatment offered in and within the physical environments of the asylum (Sachs 1999, 239), but these very provisions were also seen as ultimately beneficial for the care and recovery of mentally ill patients (Grob 1985, 641). 
During the nineteenth century, South African asylums adopted and were guided by moral therapy. This can, in large part, be attributed to the fact that many of the asylum doctors were recruited from Europe and brought with them the management strategies and philosophies of moral therapy (Burrows 1958, 291; Deacon 1996, 291; Parle 2007, 16; Plug and Roos 1992, 218-219; Swanson 1994, 8; Swartz 1996, 7). The bases and precedents of this internationally disseminated mode of moral therapy and its theory and practice in South Africa have been explored by a number of authors (Deacon 1996, 288; Deacon 1999, 108-109; Deacon 2003, 22; Parle 2007, 42-46; Plug and Roos 1992, 221; Swanson 1994, 71; Swartz 1996, 27-28). For the purposes of this essay, only the particular mode of moral therapy that was offered at Grahamstown Lunatic Asylum will be outlined. In the discussion that follows, emphasis will be placed on the recreational and occupational activities offered at the asylum. It is important to underscore that moral therapy promoted an understanding that everyone and everything in the patient's environment influenced their mental condition and that activities associated with them in particular possessed therapeutic potential (Sutton 1986, 35). However, recreational activities were reserved for the white private patients. Consequently black patients were mostly limited to occupational activities. Such differential therapy and other ways in which moral therapy practised at the asylum came to be affected by the race of the patient (Swartz 1995b; 2008; 2009), are primary concerns that are addressed in the essay.

The Grahamstown Lunatic Asylum opened in 1875 with Dr Robert Hullah acting as the first superintendent from 1875 to 1890 . In the discussion that follows, it will become evident that, although Hullah strove to institute moral therapy as the chosen approach to treatment, there were considerable deficiencies in his management (Swanson 1994; Swanson 2001; Swartz 1995b). A key theme outlined in Hullah's 
annual reports was a focus on the various forms of entertainment offered at the asylum. For example, in the Christmas of 1879, a musical piece, Beauty and the beast, was performed for the patients (CCP 1/2/1/43). Other forms of entertainment over the years included firework displays, musicals, dramatic performances and picnics (CCP 1/2/1/46; CCP 1/2/1/50; CCP 1/2/1/55; CCP 1/2/1/71; CCP 1/2/1/73). However, entertainment offerings were only one aspect of a broader regimen of therapeutic activities offered under the auspices of moral therapy. The treatment stressed the potential capability of patients to recover lost reason through useful engagement and recreation in pleasant and cheerful settings (Hawkins 1991, 74). It was specifically in terms of these activities that the asylum was deemed lacking. In the 'Report of the committee of Visitors of the asylum' for the year 1879 (CCP 1/2/1/43), the Committee stressed the asylum's conspicuous failure to provide suitable activities for the patients. For the Committee (CCP 1/2/1/43) this lack of provision was indisputably at odds with the stated aims of moral therapy:

To rise at 06:00 and to have nothing to do between meals but walk up and down a courtyard or sit or lie down under a veranda and to be sent to bed at 18:00 is a mode of life that does not seem to us in accordance with the principles that are now generally accepted for the treatment of lunatic patients.

In the Inspector of Asylums report for 1889, the report identifies a number of recurring problems that show a continuation of the 1879 Committee Report. In particular, reference is made to the fact that tea is served at $5 \mathrm{pm}$ and that the patients are in bed by 6pm, which leaves no time for evening recreation (CCP 1/2/1/77). The importance placed on improving the asylum, as signalled by these reports was, in part, due to the intention of the Cape Colony to use the asylum for the treatment of acute and recent cases of insanity (CCP 1/2/1/77). The first significant steps made in this regard commenced with the appointment in 1890 of Dr Thomas Duncan Greenlees as the 
asylum's new Medical Superintendent. Greenlees made substantial progress in effecting a number of changes to the asylum to make it better equipped to serve such purposes. In an effort to enhance the array of activities on offer at the asylum, he introduced picnics at Port Alfred and Sand Drift, dances, dramatic entertainments, concerts, magic lantern entertainments, social evenings, cricket, an instrumental band and croquet and lawntennis for the women (CCP 1/2/1/79).

Attention was also placed on increasing single room accommodation to add to the personal comfort of the patients and wards were refurbished to make them brighter and more cheerful. Lastly, altering the patients' bedtime to $8 \mathrm{pm}$ afforded them the opportunity to enjoy some form of recreation in the evenings (CCP 1/2/1/79). These changes received high praise from Dr Dodds, the Cape Colony's Inspector of Asylums, ${ }^{4}$ and were emblematic of his motto for the asylums in the Cape, namely "... to cure the curable and to brighten the lives of those that cannot be cured" (CCP 1/2/1/79).

The activities on offer at the asylum increased in number and variety and continued to be a focal feature of the annual reports between 1891 and1900 (CCP 1/2/1/108; CCP 1/2/1/112: CCP 1/2/1/115). These included cards, billiards, draughts and other games. Attending entertainment events in Grahamstown became more frequent and added variety to the patients' lives through experiencing new surroundings (CCP 1/2/1/82). A crucial thrust in Greenlees' (CCP 1/2/1/92) approach was to avoid monotony from setting into the patients' lives:

Altogether, I know of few Asylums where such efforts are made to provide amusement, instruction and recreation to the patients. Hardly a day passes but something or other is 'on' and our resources are often put to the test to introduce new and varied means of amusement, for repetition in these as in many other things has the effect of producing that monotony it is their object to dissipate. 
A direct outcome of the various improvements was an increase in the number of private patients who wished to take advantage of the asylum's "curative agencies" (CCP 1/2/1/82). More paying patients was not only serenaded as a sign of the asylum's growing popularity (CCP 1/2/1/108), but the trend also led to the construction of new buildings to provide first-rate accommodation for "gentlemen paying the highest rates of board" (CCP 1/2/1/112). The provision made for accommodating private patients and the uptake by such individuals helped to make the asylum the most cost-efficient asylum in the Cape Colony (Marks 1999, 276; Swanson 1994, 21).

By offering a number of facilities and services to cater for private patients, the asylum - under the management of Greenlees - came to closely resembling a convalescent home (Swanson 1994, 82; Swanson 2001, 134). Accordingly, the care offered at the asylum was not only concerned with treatment or therapy, but also with caring for the material needs and social activities of private patients too (du Plessis 2012, 31). Apart from privileging private patients, Greenlees' superintendency was also marked by the differential treatment of black patients (Swanson 2001, 17; 134). To elucidate further, at the asylum, Greenlees effectively created two asylums, each with its own distinctive ethos. On the one hand, it offered white paying patients a milieu that was therapeutic, comfortable and based on social class values. On the other hand, for black patients the asylum was primarily conceived as a workhouse in which manual and even hard labour were to be performed (Swanson 1994, 25-6).

This differential treatment was not an idiosyncrasy of Greenlees alone. It came to define the provision of care in the Cape Colony asylums at the turn of the century. Moral therapy offered remedial occupation and recreation, yet both options were not available to all patients. White patients were predominantly occupied with recreational activities - from sport, indoor games, plays, dances and excursions - while the black 
patients were mainly limited to manual labour such as farm work and laundry (Swartz 1995b).

With particular reference to the Grahamstown Lunatic Asylum, black men were excluded from recreational facilities and were primarily limited to providing manual labour for the asylum undertaken in the guise of occupational therapy. Black women were confined to the asylum buildings where they performed domestic duties like cooking, cleaning, washing and ironing (Swanson 1994, 24; Swanson 2001, 134). These domestic duties were so essential to the optimal running of the asylum that they surpassed the benefits of regular outdoor recreation for black female patients. This is most apparent in Greenlees' failure to ensure that the black female patients were given daily walks. He also pointed out that this would disrupt their work in the laundry, and therefore hinder the operational needs of the asylum (Swartz 1995b). In sum, black patients were deployed as an unpaid labour force within the asylum (Swartz 1995b; Swartz 1999, 154).

One basis for the differential treatment of black patients was the popularly held prejudice that they suffered from simpler forms of insanity when compared to Europeans. Greenlees (CCP 1/2/1/79), like most Victorian psychiatrists, held the conviction that the more serious forms of insanity could only occur in "persons of a higher mental development" (CCP 1/2/1/79) such as Europeans. The simpler forms of insanity were marked by faster recuperation, which accounted for the high recovery rate of black patients figured at $68.75 \%$ for black men and $57.14 \%$ for black women while in white men the recovery level was only $29.17 \%$ and in white women it was as low as $28.17 \%$. For Greenlees (CCP 1/2/1/79), the statistics were taken to mean that the treatment of black patients at the asylum was quite adequate but added that, in order to ensure the recovery of white patients, the highest level of care and treatment was 
required. Such an argument put in place practices that had racist effects. Forging discriminatory treatment regimens resulted in white patients receiving better care than black patients (Swartz 2009, 71).

The asylum not only offered differential treatment based on the race of the patient but also strove to physically separate white from black patients. The reason for this was the belief that contact and relations with patients of a different race would slow down and impede the recovery process and be discourteous to the sentiments of white patients (Swartz 1995b). In regard to the latter point, it is important to indicate that the act of racial partitioning was for Greenlees (CCP 1/2/1/89) based on serving the interests of the private patients:

... there is a strong feeling in this part of the Colony that European and native cases of insanity should not be treated in the same building; or if complete separation is not feasible, that arrangements should be made to house them in buildings quite apart from those occupied by Europeans. There is much to be said in favour of this plan: when it is considered that no asylum in the Colony can boast of such a large income from private patients as this institution - some of these cases paying as much as $£ 33$ s. per week - surely some consideration should be given to the natural prejudices of their friends, that their afflicted relatives should not be allowed to associate with the native.

The discussion thus far has drawn attention to Greenlees' focus on providing for the interests of private patients. This implies that the form of moral therapy that he offered to the private patients included provision for the comforts and activities associated with their social class. In other words, the asylum did not strip the private patient of the social and class privileges of their life prior to institutionalisation. Rather, one can argue that moral therapy recognised the importance of maintaining the prevailing societal class norms in order to underscore its ideas of pertaining to humanitarianism, health and healing (du Plessis 2012, 31). 
Equally important to Greenlees was the promotion of the asylum to prospective private patients. One way in which Greenlees constructed a public image of the asylum as committed to the curative regime of moral therapy was through the publication of the asylum's very own periodical, the Fort England Mirror. A deliberate point was made to ensure acknowledgement that the asylum reflected the tastes, proclivities and activities of private patients. The periodical aimed to offer amusement and instruction to the patients and the outside world at large (CCP 1/2/1/92) but it also propagated and marketed an image of the asylum as being dedicated to providing an appropriate setting for patients to regain their serenity. What is of particular significance is that the periodical was submitted to a number of medical journals including the South African Medical Journal and The Journal of Mental Science. Both journals specifically acknowledged receipt of the periodical and even at times provided a summary of the key points for their readership. Furthermore, the editors of the journals shared their satisfaction with the administration of the asylum while commending the asylum for the high degree of recognition it placed on therapeutic activities. These included, for example, the establishment of the asylum's very own Fort England Cricket Team and a week spent at a hydropathic establishment (Reviews and Notices 1894; The Fort England Mirror 1893).

The Fort England Mirror included a number of photographs (CCP 1/2/1/84) that were used to illustrate the activities offered at the asylum. Additionally, a set of photographs of the asylum had been sent to the Colonial Office for the "purposes of future reference" (CCP 1/2/1/84). The ambiguity of such purposes is later qualified when Greenlees (CCP 1/2/1/84) grandly states that the photographs “... should prove of immense value in the future history of the asylum, and it was partly with this object that I took them." Yet Greenlees' objective in taking the photographs challenges the 
traditional purposes intended for psychiatric photography (the physiognomic paradigm) and it is at odds with the reigning myths and iconography of madness (visualising madness as 'difference'). In order to indicate the full extent of Greenlees' departure from such institutional roles of photography and the models of visualising madness, the dominant formations of each of these are now discussed.

\section{The dominant formations of photography and madness}

A dominant myth that permeates the discourses of madness is that it is readily visible and marked in the individual. The iconography of madness mainly focuses on the outer and/or external appearance of the individual which can include: wild, unkempt hair; tattered clothing; red-veined, staring eyes; an angry attitude; wearing poor clothing; nakedness; and an animalistic, wild or beastly posture and poise (Andrews 2007, 6; Buda 2010, 279; Cross 2004, 199; Cross 2010, 131; Gilman 1996; Houston 2003, 54; Porter 2001, 43). These icons arise out of a shared belief that madness entails a loss of humanity and civilization (Andrews 2007, 6). Their function is also to construct madness as visibly and inherently different in appearance and behavior to sane individuals. In doing so, the icons are instrumental in demarcating a symbolic binary of sane versus insane (Cross 2004, 199; Gilman 1988, 13).

The myth of madness as 'difference' and its associated icons were disseminated and entrenched in both the visual and performing arts (Buda 2010, 279; Cross 2004, 199; Cross 2010, 131; Gilman 1996; Houston 2003, 57). The overarching visualization of madness was equally evident in medical literature, science and popular conceptions (Andrews 2007, 6; Houston 2003, 51). In terms of medical literature, the myth of madness being identified by external appearance was investigated in the 'science' of physiognomy. For Johann Lavater, the physiological features of an individual - the 
shape of the nose, the colour of the eyes, the structure of the head and frame - were characteristics that indicated the predisposition to mental illness (Gilman 1988, 24; Sekula 1986, 11). The influence of physiognomy in the study of mental illness is clearly identifiable in illustrations appearing in medical books identifying types of insanity by their physical appearance (Logan 2008). By the 1870s the visualization of mental illness was widespread in medical literature and was illustrated by photographs (Davis 2006, $64)$.

The first exponent of photography for the recording of the physiognomy of insanity was Hugh Welch Diamond (1809-86) (Gilman 1976, 8). In 1856 he presented a paper titled 'On the application of photography to the physiognomic and mental phenomena of insanity' to the Royal Society on his theories regarding the use of photography in the practice of psychiatry (Buda 2010, 279; Gilman 1976, 8). Diamond's paper argued that photography provides three important functions in the treatment of the mentally ill. First, and in accordance with the theories of physiognomy, Diamond postulated that photography accurately captures the external markers of internal disturbances and thereby "... exhibits to the eye the well-known sympathy which exists between the diseased brain and the organs and features of the body" (Diamond 1976, 20). Second, photography can be used in the treatment of the mentally ill through the presentation of an accurate self-image (Gilman 1976, 8). Third, and lastly, by recording the appearance of the patients, photographs provide a valuable tool for aiding the identification of patients in cases of re-admissions (Diamond 1976, 2324).

Diamond's delineation of the uses of photography in psychiatry is hinged on physiognomy's belief in the presumed direct relationship between outward facial characteristics or expressions and mental health (Amirault 1993, 59; Godbey 2000, 41). 
Furthermore, such an expression premises the notion of photography as an objective and transparent record of the real. To elucidate further, Diamond $(1976,24)$ proclaims that photography provides “ ... a perfect and faithful record, free altogether from the painful caricaturing which so disfigures almost all the published portraits of the Insane as to render them nearly valueless either for the purposes of art or of science." This belief in the supposed objectivity of the medium is problematised by Gilman (1976; 1988). Perceptively, Gilman reveals that Diamond's images are reflective of the portrait photographs of the period (Gilman 1988, 41). For Showalter $(1987,87)$ the resemblance of Diamond's photographs to artistic portrait photographs indicates that they should be analysed not as 'objective' or 'scientific' accounts but rather explore the visual conventions - the props, poses and aesthetic models - adopted from the arts. The aim of this notion is to reveal how Diamond's photographs are intertextually linked to aesthetic structures and models in order to ensure the greatest visual effect on the observer (Gilman 1976, 9). Overall, Diamond's photographs provide a practical indication of how the discourses of psychiatry, physiognomy, photography and aesthetics coincided and overlapped (Cross 2010, 61).

Although the contemporary re-readings of Diamond's notions draw attention to aesthetic structure of the photographs and question the objective and scientific values of physiognomy, Sekula $(1986,12)$ cautions against readings that fail to recognize the enormous popularity of the physiognomic paradigm and its wide-reaching influences. In the later decades of the nineteenth century, Diamond's work proved to have had a significant influence on psychiatric communities across Europe as is evident, for example, in the studies by the infamous Jean-Martin Charcot (Buda 2010, 280). More troubling though is that photography became somewhat entrenched with the message to both professional and lay audiences that the mentally ill had distinctive physical 
characteristics (Godbey 2000, 41). For psychiatry, this meant that photography became a diagnostic tool deployed by the clinical gaze to recognize the appearance of madness (Berkenkotter 2008, 56). ${ }^{5}$

\section{Photographs for public consumption}

Although the dominant discursive formation of the nineteenth century saw the recording of physiognomy as the rationale of photography, there were other purposes of photography that lay outside of Diamond's entrenched uses, yet they did fall within the growing professionalization of psychiatry as well as the ethos of moral therapy. The raison d'être of moral therapy was the possibility of a cure derived from the restorative features of the asylum environment and the activities that took place within it. This potential was not only the guiding philosophy of asylum establishments but was also overtly disseminated as an important element in annual reports and other documents for public consumption (Guyatt 2004, 55). Many reports and documents included photographs of the asylum that recorded the therapeutic activities on offer (Bogdan and Marshall 1997, 24; Guyatt 2004, 51). These photographs assisted in constructing a public image of the asylum as curatively orientated (Godbey 2000, 36-37). To explore further, the broader curative technique of the asylum within moral therapy aimed to return the insane to sanity and normal life. In order to connote this, photography captured the indoor activities at the asylum which were shared with the outside world. The motive behind this was to show that the patients did have the potential to interact with each other and could be part of wider society. In other words, the events of the asylum could be mistaken for those of ordinary life. Thus, the photographs of such activities blur the visible markers between the asylum and the outside world (Godbey 2000, 50; Wynter 2011, 46). 
Beyond indicating the activities offered at the Grahamstown Lunatic Asylum, the photographs that Greenlees disseminated for public consumption significantly include a large number of representations of patients. The patients depicted looked and appeared normal and thus provide an offset to the iconography, myth and tropes of madness as 'difference'. Figure 1 is emblematic of the images commissioned for public

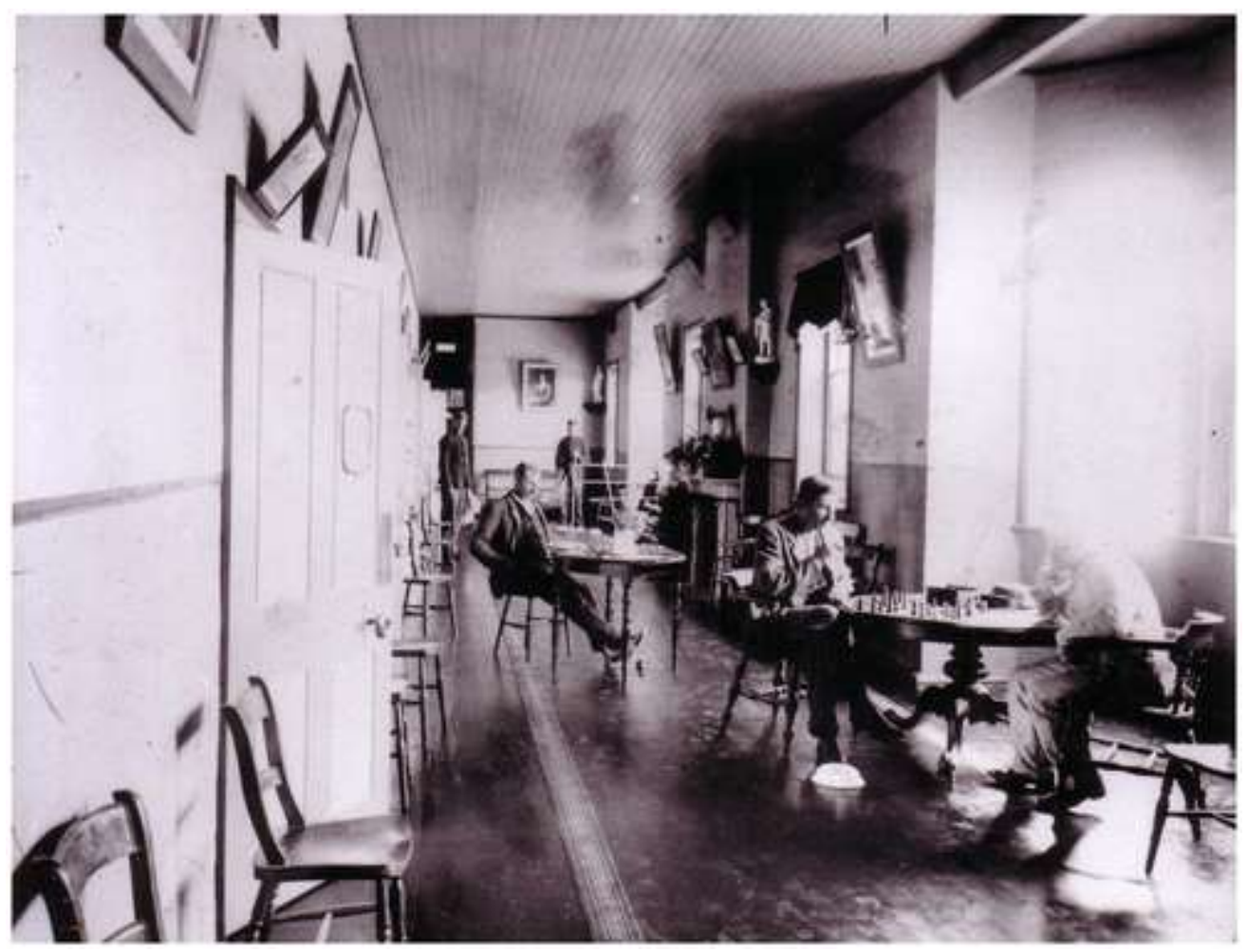

Figure 1. Passage in the Fort England Asylum, Grahamstown showing period furniture, c.1890s. Reproduced by permission of the Western Cape Archives and Record Service, reference number: A.G. 421.

consumption. The photograph depicts a number of well-dressed men in the interior of a neatly decorated room. What is striking is that none of the men show any of the stereotypical icons of madness. Instead of visualizing madness, Greenlees sought to lay emphasis on the normalcy and civility of the patients. In doing so, the photographs are reminiscent of the depictions evident in Isaac Kerlin's series of photographs for his volume The Mind Unveiled (1858) which stress the normalcy of the subject's 
appearance and emphasise their ability "... to return to the world outside the asylum, to be normal as well as appear normal" (Gilman 1996, 172). Although the photograph does not represent the stereotypical markers of madness it may still be reliant on them to communicate the curative aims of the asylum. In other words, the appearance of normalcy as indicative of health, healing and restoration is only achieved because it is set against non-normalcy being expressive of illness and lunacy. Thus, Greenlees may not necessarily be challenging the trope of madness as 'difference' but operating within it to communicate the normalcy of the patients as connotative of restored sanity and health.

This interpretation does not seek to discount Greenlees' attempts to counter the prevailing tropes of visually representing insanity but maybe reveals the difficulties, contradictions and tensions in trying to offer alternatives to the dominant formation. Thus, Greenlees may have sought to depict the normalcy of his patients as a product of the asylum's therapeutic regimen, but the connection between normalcy and healing is only recognised because it is juxtaposed with the aberrant and deviant being associated with madness (Gilman 1996, 233).

In Greenlees' photographs, not only are notions of normalcy revealed to be ensnared in a visual economy, but any possibility of suspending the myth of madness as 'difference' is restrictive to certain visual strategies. What becomes apparent is that the strategies of visually negating madness as 'difference' are hinged upon representations of wealth and class (Sidlauskas 2013, 8). For example, Figure 1 captures a finely decorated room populated with patients of high-class, well-mannered, gracefully distinguished and civilised. Thus, it is in privileging images of the indoor interiors and activities afforded to paying patients that Greenlees is able to suspend the myth. 
The focus on wealth and class in the photographs is not covertly alluded to but is explicitly evident. The reason for which is that asylum photographs not only constructed a public image of the asylum as curatively orientated but they also acted as a sales tool (Godbey 2000, 36-37). The public image that Greenlees sought for the asylum was a curative institution for private patients in recent and acute cases of insanity. Greenlees' focus on the public image of the asylum was shared by the broader psychiatric profession that were preoccupied with image making (Topp 2007, 241). The widespread importance placed on the image making of the asylum is ascribed to how it functioned to promote and popularise the asylum as the best treatment option for private patients. Therefore, the indoor activities photographed in Figure 1 indicates not simply the high standard of care offered, but they also portray the caring provided to meet material needs and illustrate the social activities in which private patients engage. Thus the asylum showed a connection and correspondence to outside social norms in which private patients lived in an environment of material abundance.

In the light of this discussion, Greenlees may not have necessarily aimed to counter or suspend the tropes of madness as 'difference'. Instead he mobilised only certain visual conventions and elements in constructing the restorative and recuperative potential of the asylum. Rather than having variable and multiple representations of the patients, the model of the (in)sane patient that Greenlees constructed is solely coded as middle class or higher, swaddled in the material culture and comforts befitting such a class of patients. This image of the asylum and its patients was constructed to actively appeal to and persuade the public of the asylum's suitability in caring for private patients, and to show how its setting is conductive to healing and a return to society. Thus Greenlees' photographs may initiate discussion on reconfiguring madness as 'difference' but further debates and analysis are required. Greenlees' images of the 
(in)sane are mediated by class and wealth and may be more compellingly read as a marketing tool for gaining an increase in private paying patients.

It is evident that Figure 1 is not indicative of the entire asylum nor is it representative of the treatment and care offered to all patients (Godbey 2000, 51; Guyatt 2004, 52). Yet there are also photographs of black patients distributed for public consumption. Consequently questions regarding how black patients fitted into the public image of the asylum thus come to the fore. What did the asylum wish to portray in terms of its care or treatment for the black insane? How did the care and cure of black patients relate to the broader imperialist ideology of the late nineteenth century?

In the photographs of black patients their differential treatment is instantly recognisable. In the photographs of the ward interiors for black patients there are only chairs that overlook the bleak and austere blank walls. ${ }^{6}$ The chairs are neither positioned for the patients to gaze out into the garden nor to facilitate being engaged in conversation or indoor recreational pursuits. Unlike Figure 1, there are no tables for board games or recreational activities. Glaringly conspicuous though, is that no patients are seen to be indoors. The ward is vacant of patients and void of any ornament, aesthetic decoration or expression of sentiment. In order to locate the figures of black patients, one finds them represented only outdoors and mainly in various form of labour pursuits such as farming. ${ }^{7}$ The photographs are an unmistakable visual record of how black patients received a variant of moral therapy that was marked by exclusion from recreational pursuits while primarily providing unpaid labour for the operational running of the asylum.

Although such photographs provide a significant illustration of the differential treatment regimens offered to black patients, to indicate how the representation of the black patients relates to the public image of the asylum, further examination of studies 
in colonial psychiatry and the representation of the black insane are required. The asylum for black patients was no doubt similar to a workhouse but was not carceral in the sense of imprisoning patients to lifelong institutionalisation. Instead, the asylum for black patients was also shaped around discourses of cure (McClintock 2001, 28). Thus for both black and white patients the asylum's public image was determinedly focused on signifying curability, restored sanity and a return to society. However, the visual conventions for connoting black patients as 'cured' is distinctly dissimilar from the codes governing the representation of white patients.

While representations of the asylum's curative regime for white people was coded by signs and symbols of wealth and class, the following paragraphs will outline how cure and recovery in representations of black patients were marked by docility. The basis for docility becoming a marker of recovery is that it is a binary opposite to the nineteenth century trope of the black insane as an ignoble savage. Accordingly, in the discussion that ensues, attention and emphasis will be first placed on nineteenth century stereotypes of the black insane and how they figure in Greenlees' theorisation.

The dominant stereotype that figured the black insane in the nineteenth century is defined by Gilman $(1985,140 ; 1996,112)$ as the ignoble savage. This construction was the counterweight to the noble savage that lacked illness (Gilman 1985, 140; Gilman 1996, 112). In Greenlees' $(1895,73)$ academic text, the trope of the noble savage is employed to explain the absence of certain forms of insanity in the black population:

[The] absence of general paralysis is not an extraordinary fact when we consider the simple mode of life of these natives; no cares and no struggle for existence such as is found in European cities. Living a life in the open air, in a perfect climate, with plenty of simple and natural food, it is not to be expected that diseases originating in mental worry and anxiety should make themselves evident. 
Greenlees $(1982,14)$ also invokes the trope of the noble savage to explain the so-called innate characteristics of black people who are described as being "... for the most part willing servants, and naturally look up to white people as far above them in knowledge". In this regard, the trope of the noble savage is venerated by Greenlees as it consistent with the ideal colonial relations of the colonised submitting to the coloniser.

The trope of the ignoble savage emerges in Greenlees' discussions of blacks living in close contact with Europeans and incapable of upholding moderation in the face of the temptations arising from civilisation - such as alcohol (Swartz 1995b). This is explicitly recorded in Greenlees' $(1895,74)$ asserting that one of the main causes of insanity in the black population was excessive drinking. Thus, the cultural contact of the black population with European civilisation was blamed as the cause of insanity (Jackson 2005, 71-72; Swartz 1995a, 46; Swartz 2008, 287-288). This was further bastioned by the belief that blacks either lacked an ability to adjust to 'culture contact' (Jackson 2005, 70-71) or were simply not equipped to cope with civilisation (Vaughan 1991, 107). Both scientists and the public alike were so convicted by such beliefs that they were certain that the inhabitants of the colonies in the nineteenth century were in the process of cultural and physical deterioration (Wittaker 2009, 131). Sharing such sentiments, Greenlees $(1895,75)$ confidently forecasts that “ $\ldots$ the time will soon come when civilization will overshadow them with its baneful pall, bringing innumerable diseases in its train, and ultimately exterminating all races that oppose its progress." In order to elude extermination, the only recourse offered to the colonised by the coloniser was to accept civilisation and assimilate appropriately into it (Wittaker 2009, 131).

For colonialism, assimilation into civilisation meant docile black bodies as a labour force for the white population. Instead the colonists found themselves in the presence of mounting numbers of black men in metropolitan areas who were neither 
docile nor domesticated (Swartz 2008, 287-288). The undomesticated black man presented a threat to white society by disrupting work regimes and relations or refusing the social roles that colonial society assigned to them (Deacon 2003, 27; Jackson 2005, 70; Louw and Swartz 2001, 13; Swartz 2009, 72; Vaughan 1991, 125). The mentally ill black men, who came to be noticed by the authorities, were precisely those who were undomesticated: those that had difficulties in work relations or posed a threat to colonial society (Swartz 1995b).

Though the admissions of the black insane to the asylum remained modest, ${ }^{8}$ the spectre of the black insane as an ignoble savage resisting colonial rules and order reflected the trepidations of colonial society. Thus, the ignoble savage is gauged to be directly linked to the coloniser's fears of undomesticated black men in colonial urban space (Jackson 2005, 70). Consequently, the public image of the asylum as curative for black patients is constituted by themes of domestication and docility. This notion is best articulated by McClintock $(2001,28)$ pronouncing that "To be incarcerated in an asylum was to be domesticated: to be made docile and demure, and above all to be put to proper forms of work." Thus the curative ideal of the asylum for the black patient is based on making pliable and docile workers (McClintock 2001, 28). In doing so, the asylum's public image is publicised as being primarily concerned with correcting black bodies to return to civilisation as a docile and obedient labour force. ${ }^{9}$

In this formation, a large number of the photographs of black patient labour in the asylum are explicitly evident of the public image of the asylum. For the purposes of this essay, I am more concerned with how docility and domesticity can be conveyed in the photographs without mobilising the established signs and symbols of labour. To do so, I will examine Figure 2 titled 'The male stoep [veranda] for blacks'. 


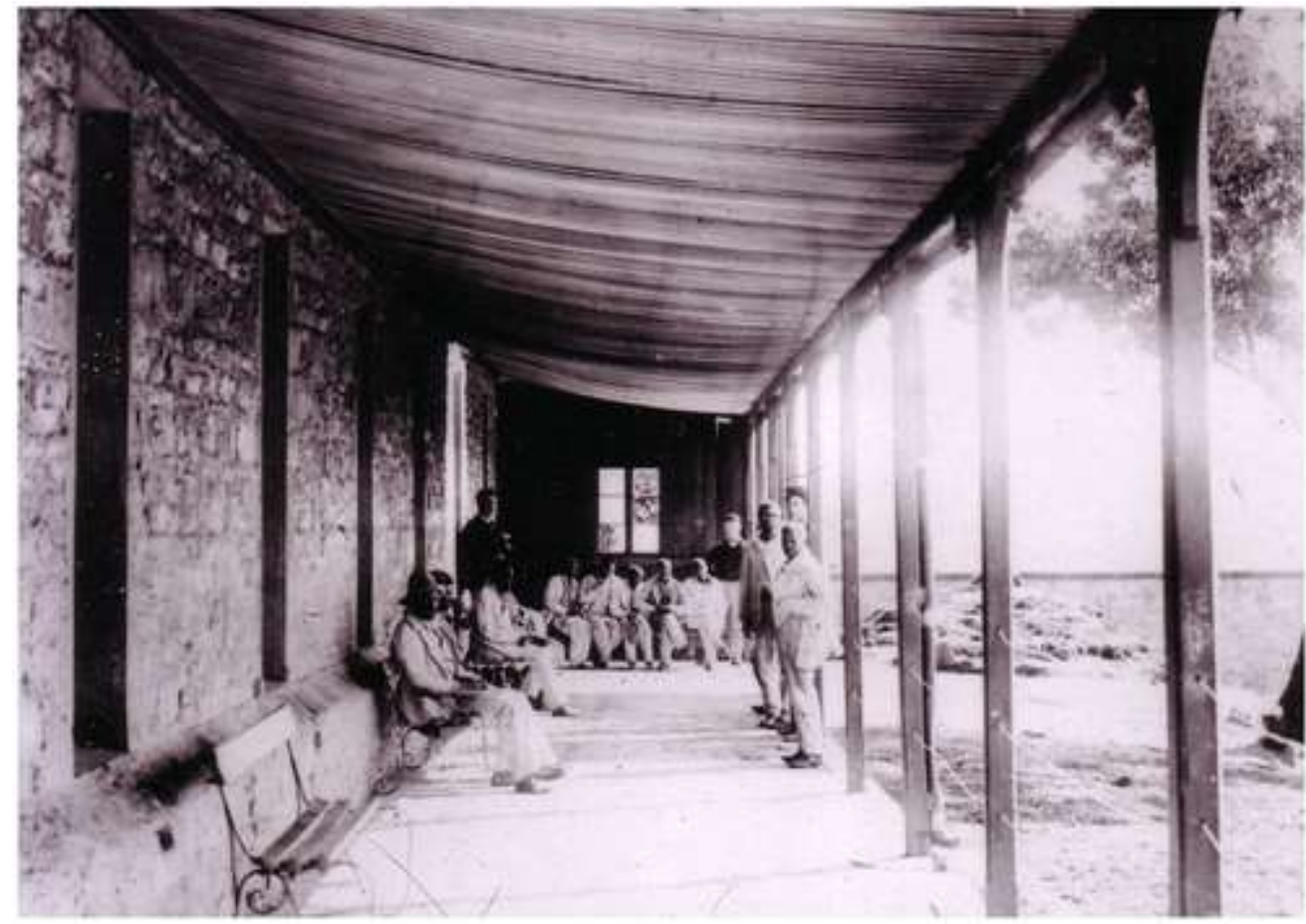

Figure 2. The male stoep for blacks, Fort England Asylum, Grahamstown showing inmates, c.1890s. Reproduced by permission of the Western Cape Archives and Record Service, reference number: A.G. 400.

Depicted in Figure 2 are a number of black men in uniform dress on a porch in what appears to be a dreadfully stark setting. Absent in the image is any indication of recreational activities, furniture (apart from a few worn benches) or decorative features. As already explored, the various absences in the image can be accorded to the differential treatment offered to black patients. The elements in the photograph that indicate docility and domestication are evident in the collective cooperation of the patients in their facing the camera. Furthermore, the patients pose at the bidding of the photographer or asylum attendant to a specific composition or arrangement. These formalist elements highlight the direction and control that the photographer or asylum attendants wielded over the patients - they surrender to the camera's lens and are at the bidding of the photographer (Showalter 1987, 97). Revealing is the passivity of the patients and their submission to the instructions of the asylum staff. 


\section{Casebook photographs}

The discussion of Figure 2 envisions photography as an apparatus that attests to the curative intent of the asylum and its relation to broader colonial imperatives: docile black bodies. The photograph captures the black patients as passive objects at the bidding of the attendant with the camera against the background of a scene that represents the asylum's regime. Yet, the passivity that the photograph captures can be argued to be undermined by the nature of power and power relations. What lies outside the frame of the photograph, in the minutes preceding the sound of the shutter, is an institution in which control and coercion, surveillance, discipline and punishment are omnipresent and serve to correct any and all imperfections. However, as such unyielding domination enfolds, forms of resistance unfold.

To substantiate further, Foucault (1979:95) upholds that "Where there is power, there is resistance". In this particular formation, there is a multiplicity and plurality of resistances that come to the fore in any power relations or relationships (Foucault 1979, 95-96; Foucault 2006). Accordingly it becomes imperative “... not to envision mental illness merely as the violent imposition of a carceral discourse on hapless colonised people" (McClintock 2001, 29) but to investigate refusal and resistance as an important part of the histories of madness (Parle 2007, 13). In this regard, I wish to complicate the public image of the asylum by discussing the casebook photographs of the asylum which depict the patients' confrontation and resistance to the asylum's regimen. Thus, the casebook photographs are argued to be valuable in recuperating active resistance and, as Wittaker $(2009,124)$ observed, hold the potential to undermine the public image of the asylum as a visual fiction.

The ensuing discussion is also able to offer a tentative approach to the history of psychiatry from the patient's point of view. For Roy Porter in his seminal article entitled 
'The patient's view: doing medical history from below' (1985), presents a central argument that the history of medicine is primarily a physician-centred account. Yet this may be a major historical distortion as it neglects to account for the patient role and the two-way encounters between doctors and patients (Porter 1985, 175). Porter's text has greatly influenced the historiography of medicine and is heralded as a 'modern day classic' (Condrau 2007, 525; Hamlett and Hoskins 2013, 2). Yet the quest to locate and analyse the patient's voice is fraught with a number of pitfalls. The most glaring difficulty is the lack of available sources as patients' voices are largely absent from institutional records (Jones 2012, 59). Although there is a wealth of documentation, including casebooks and letters to colonial authorities that pertain to asylum governance and the practices of psychiatry, the patient's voice and views remain largely lacking from the colonial archive (Swartz 1999, 156; Swartz 2005; Swartz 2008, 291-292).

A second pitfall may pertain to analysing any traces or vestiges of patients' voices in the colonial archive as indications of patient agency. To contextualise further, Lalu $(2009,22)$ argues that agency should no longer lay claim to the will of the individual but needs to account for the:

... ways in which agency is conditioned by the norms, practices, institutions and discourses through which it is made available. In this sense the question of agency may also be posed in terms of the practices and procedures of evidence making and the protocols of history - the social process, in other words, of the subjection of agency (Lalu 2009, 38).

By focusing on the subjection of agency, questions of agency become inextricably linked to the discourse of the colonial archive (Lalu 2009, 40). For Lalu (2009, 38-39), the colonial archive is an apparatus that functions to constitute the subject to specific form of intelligibility. One effect of this is “... the organisation and representation of colonised subjects as a subordinate proposition within primary discourses" (Lalu 2009, 
62). In other words this means that any attempt at agency is already structured in “... relation to a condition of domination" (Lalu 2009, 63).

Lalu $(2009,62)$ continues by stating that the narrative strategies of the colonial archive are capable of organising and coding our reading to such an extent that any efforts that depart from colonial constructions are considerably restrained (Lalu 2009, 41). Thus, the colonial archive is theorised as not readily lending "... itself to alternative histories that mark a break with the repertoires of colonial and apartheid narration" (Lalu 2009, 42). Although the colonial archive codes and constrains readings, I wish to argue that alternative meanings can be uncovered through analysing photographs. To elucidate further, photographs are not direct records of reality (Swartz 1996, 65). Furthermore, they do not have a unitary meaning embedded within them. Rather, photographs have multiple meanings (polysemy) and are open to numerous interpretations. Although a photographer can attempt to code an intended meaning into a photograph through the use of signs, symbols and linguistic devices, the reader may provide an entirely different interpretation based on subjective responses.

To underscore the subjectivity of the reader in the interpretation of photographs, the seminal work of Roland Barthes proves to be indispensable. Barthes $(1981,25 ; 27)$ outlines two elements that are co-present in the interpretation of photographs. The first element is titled the studium that can be defined as the average affect derived from understanding the photographer's intended meaning (Barthes 1981, 26-28). In contrast, the punctum is a detail in the photograph that disturbs the studium, and proceeds to wound, cut, pierce or prick the reader (Barthes 1981, 26-27). The punctum changes the reading of the photograph and marks it in terms of having personal value for the reader (Barthes 1981, 42). Thus the punctum pertains to a certain detail already in the 
photograph that evokes in the reader a purely subjective response, thus striking the individual reader on a personal level (Barthes 1981, 55).

Accordingly, the punctum is not coded, does not relate to the intention of the photographer but is rather subjective and hence different for everyone. The analytic strategy provided by Barthes acknowledges the multiplicity of meanings arising from any interpretation of photographs but also explores how the wounding from the punctum subsequently challenges the reader to acts of observing, discerning and reflection (Barthes 1981, 21). The latter point is significant as it allows the reader to perceive alternative or hidden meanings that may challenge or be paradoxical to the conventional (intended) message. The following analysis of the casebook photographs is guided by this theorisation.

A central argument is that the casebook photographs counter the public image of black patients as docile and domesticated. To explicate further, the details that strike and pierce me in the casebook photographs are how the postures, gestures and facial expressions of the patients reveal resistance. Thus the punctum in the casebook photographs are the signs that I regard as connotative of resistance. I foreground the instances of resistance to constitute a counter-narrative to the monolithic public image of black patients as docile. This process can be regarded as a 'hermeneutics of recovery' (Gewurtz 2006, 286) in which the gaps and omissions of black patient resistance in the textual record can be recovered through the analysis of visual records (Gewurtz 2006, 267). Accordingly, I suggest that one approach to developing a patient's view of the asylum is offered in the casebook photographs.

Cognisant of Lalu's $(2009,63)$ contention that colonial records reveal the effects of domination rather than representing the agency or consciousness of the colonised, the analysis of patient resistance is understood as indicative of the relational character of 
power relations (Foucault 1979; 2006). Thus the casebook photographs are not approached as providing an accurate gauge of all the instances, expressions and evidences of patient agency but only as providing an offset to the public view of black patients as docile.

One lasting legacy of Diamond's uses of photography for psychiatry is for medical record-keeping. Commonplace from the 1870 s to the present day is taking a photograph of a patient on admission and inserting it into the casebook or patient file (Buda 2010, 291; Gilman 1976, 9). For Sontag (1973 5; 21), the uptake of photography in psychiatry is indicative of the broader nineteenth century inclination for figuring photography as a tool for surveillance in institutions that needed to record and identify inmates or patients. Hence asylums adopted the established photographic procedures that the police deployed for the identification of individuals. These included a standardised pose in which the subject faces the camera with a neutral expression. The purpose of adopting uniform procedures would ensure that individuals can be easily identified (Didi-Huberman 2003, 55).

Recent investigations of photographs from the asylum casebooks (Bressey 2011; Hamlett and Hoskins 2013; Manzoli 2004; Sidlauskas 2013) have underscored instances of personal autonomy figured by the patient in resisting the standardised pose and uniform expression compelled by asylum procedures. For Sidlauskas (2013, 1-3), the photographs from Holloway's first casebook (1885-1889) are not representations of pathology but provide visual evidence of some of the patients' attempts at personal expression. In the photographs the patients purposefully made use of poses, costumes and expressions that they would have employed in their family portraits in order to perhaps construct and control their own clinical representation (Sidlauskas 2013, 2-3). Hamlett and Hoskins $(2013,8)$ address how patients expressed individuality in the 
Hanwell casebook photographs through the patients' presentation and embellishment as a means of individual self-fashioning. In both Bressey (2011) and Manzoli's (2004) studies, patient resistance is figured in the casebook photographs by patients refusing the camera's gaze.

In the Grahamstown Lunatic Asylum all patients on admission were photographed from 1890 onwards and their photographs were placed in the respective casebook entry that accompanied each patient (CCP 1/2/1/82). The act of photography was one of the first mandatory steps of admittance to the asylum in which it " ... functioned as ritual markers of entry into 'insane' status” (Swartz 1996, 88). Patients were not passive participants in such an admission rite but responded in a number of intricate ways. In reviewing the casebooks it becomes evident that a number of patients expressed a plurality of resistances - some that vehemently opposed submitting to the clinical gaze, others that register profound disregard for the institution, while several others may represent the ways in which the patients formulated individual ways to respond to institutionalisation.

Figures 3 and 4 pose a number of significant problems to the public image of the asylum. In the first instance they complicate the passive and docile imaginings of the asylum's curative intent. Instead of capturing submission, the casebook photographs depict an active refusal to comply with one of the first admission procedures at the asylum. Furthermore, this act of refusal reveals the hands of the attendants and nurses. In doing so, the asylum's staff are inscribed into the image. This failure of the authorities to remain hidden (Bal 1991, 42) instigates the viewer to meditate on the intrusions, discipline and conditions under which the photographs were produced (see Wittaker 2009, 121). In Figure 3 an attendant's hand is placed below the patient. The 
hand is not clenched in a fist or poised for a fight but can 'gently' correct because it is buttressed by a regime of discipline.

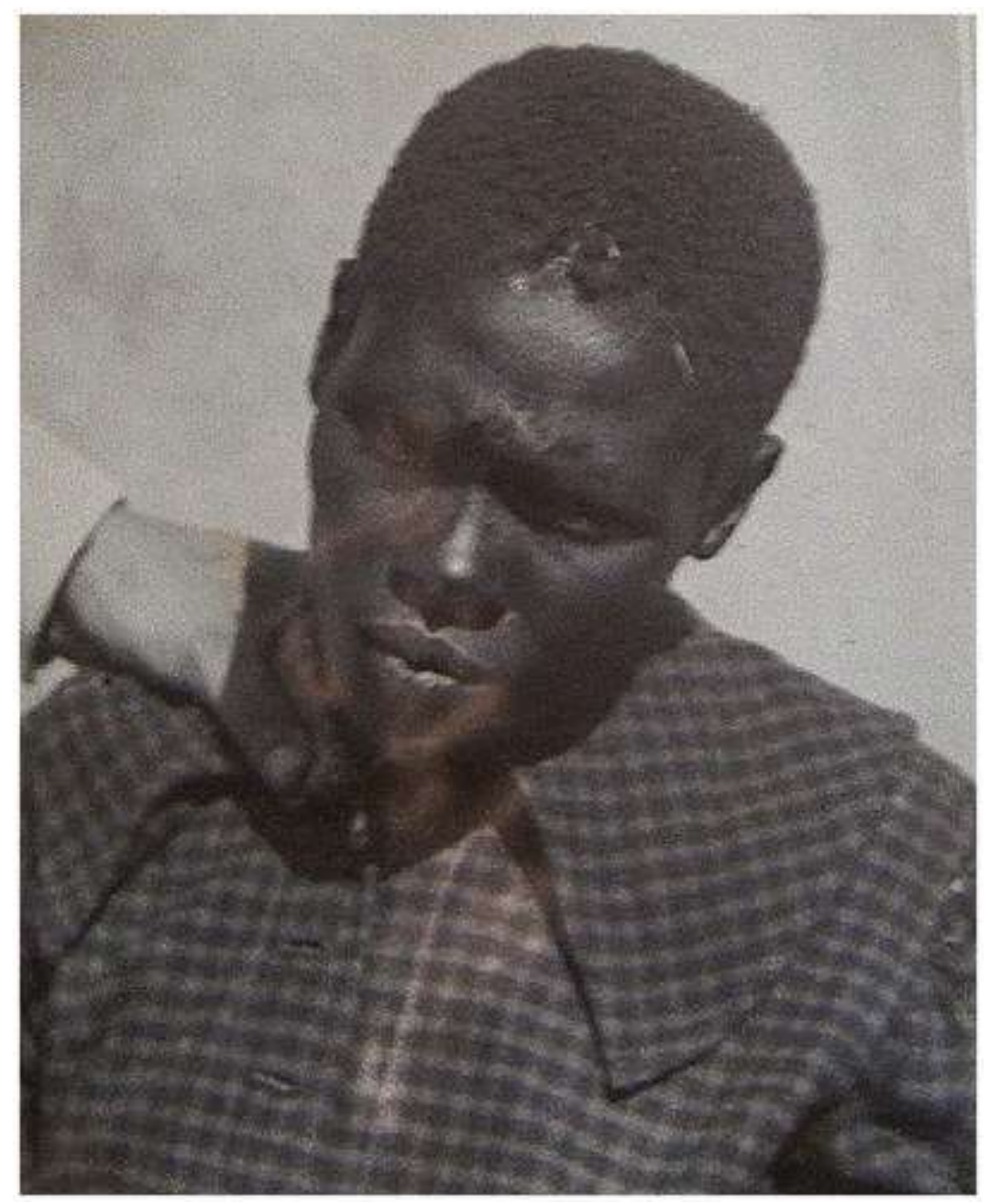

Figure 3. Patient H. Reproduced by permission of the Western Cape Archives and Record Service, reference number: HGM 20.

In Figure 4 two sets of hands are present; one set is that of a nurse who lightly coils around the patient's chin while another set of hands is sternly clamped onto the patient's head, thereby ensuring that her head faces up towards the camera. In both photographs the presence of the attendants are at hand to set the patients to the right manner in terms of the conventions required for identity photographs. Yet even under restraint or minimal correction, the patients do not offer complete complicity: the 
patient in Figure 4 closes her eyes while in Figure 3 the subject looks down away from the camera. Thus the photographs capture not only refusal to clinical gaze, and in turn, the display of discipline and correction at the hands of the attendants, but they are also able to indicate the perseverance and determination of the patients to resist the camera's gaze.

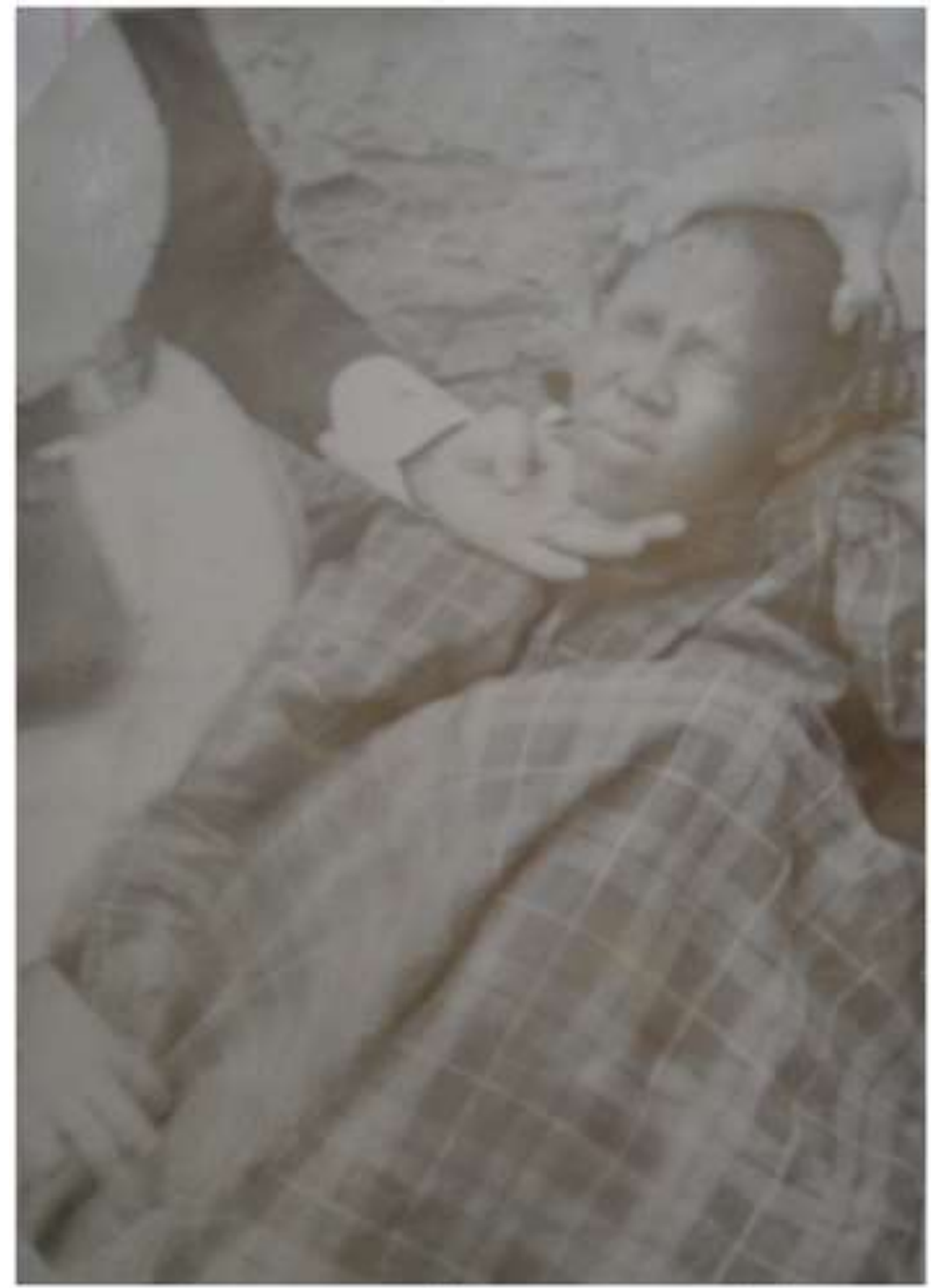

Figure 4. Patient M.L. Reproduced by permission of the Western Cape Archives and Record Service, reference number: HGM 17.

An important observation to note is that in some of the casebook photographs it is not patient refusal that figures but patients in a fearful and anxious state. In such cases, the hands of the attendants perform an act of pinning-down the patient. It is such 
images that underscore the point that the taking of a photograph is never neutral - it may even amount to constituting an act of violence against the subject (Sontag 1973). In both Figures 5 and 6 the patients are described as being easily frightened (HGM 4; HGM 18). Figure 5 is portrayed in the casebook as "A nice looking lad with an

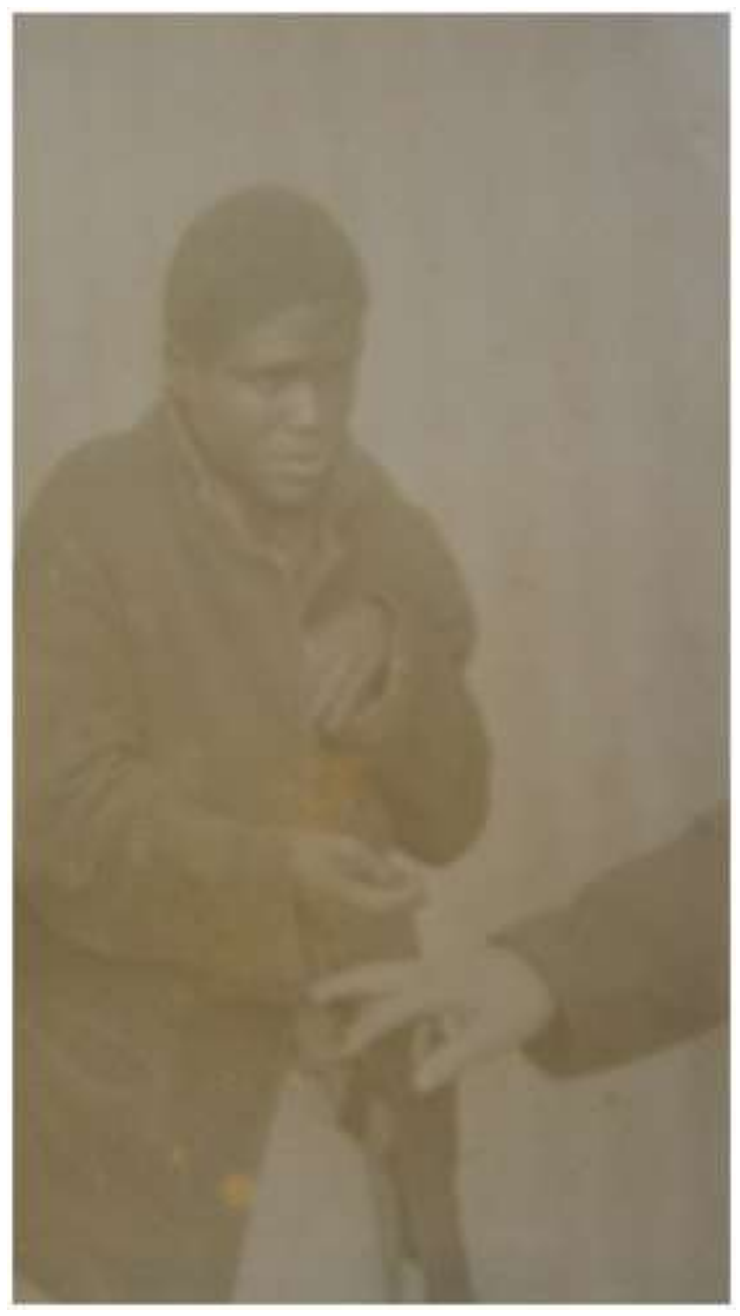

Figure 5. Patient H. Reproduced by permission of the Western Cape Archives and Record Service, reference number: HGM 4.

intelligent expression. Seems somewhat frightened, interpreting every movement into a threat" (HGM 4). In spite of this observation, the asylum still subjected him to the predatory gun-like action of the camera (Sontag 1973, 14). Yet, the hand of the attendant in this image poses a number of conjectures for the viewer. What is the role of 
the hand in the image? It is clearly not placed on the neck or head of the patient aiming at a form of correction. Furthermore, it does not restrain the patient. Could the hand be functioning to incite fear in the patient? In this reading, it may be the attendant's hand that resulted in the patient's hunched shoulders, lowered face full of apprehension and arms contained close to the body for protection. Maybe this was the exact role of the camera - to record the fear incited by the attendant - an act that would confirm the casebook entry of a 'frightful' patient. Thereby the photograph acts as proof of a condition or state that needs remedying and confinement to an asylum.

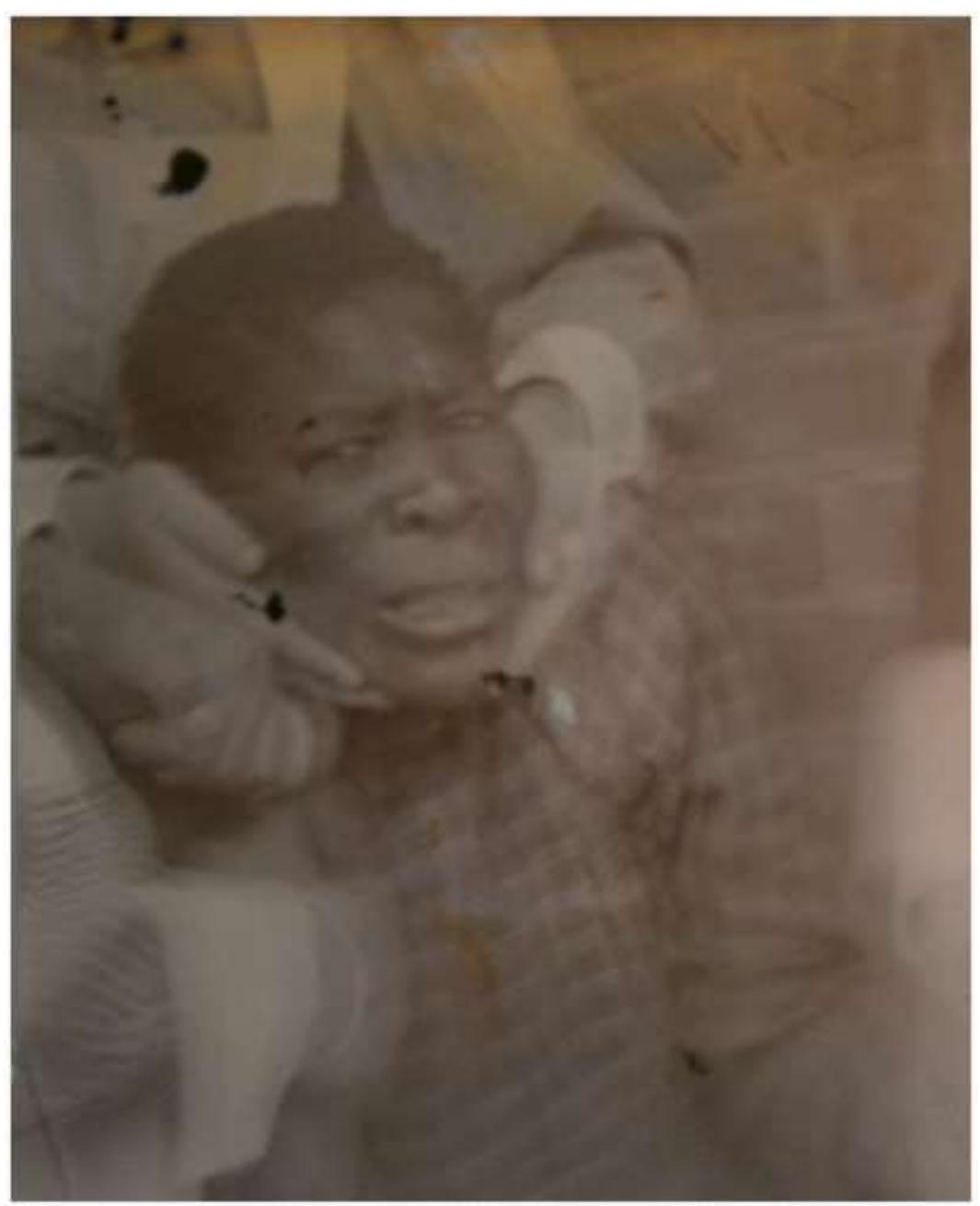

Figure 6. Patient S. Reproduced by permission of the Western Cape Archives and Record Service, reference number: HGM 18. 
The patient depicted in Figure 6 requires three attendants to contain and control her. An attendant at each of the patient's hands acts to hold them in place. This is shown to be a somewhat thwarted attempt as the image is blurred in the lower half suggesting that the patient's hands were never fully immobilised. The patient's face is clasped to be pointed in the direction of the camera. Yet, the attendants were unable to control her facial expression. Unlike the static and composed images required of casebook photographs, the face of the patient speaks of terror and fear. It bemoans an institution that practises admission rituals that are without the consent of the figure depicted; rituals that may even harm the patient by inciting fear and anxiety and thereby contributing to high levels of stress.

Scott $(1990,203)$ cautions that any refusal “ “... to produce the words, gestures, and other signs of normative compliance is typically construed - and typically intended - as an act of defiance." Thus the open refusal to comply with the asylum's admission procedures, as depicted in Figures 3 and 4, is a particularly hazardous form of insubordination. Patients who did not comply with institutional values of 'good behaviour' were secluded and or restrained. Additionally, a number of luxuries and activities would be done away with. Thus, it would be incorrect to romanticise the acts of refusal by the patients as described in these photographs. Their acts of resistance were met by confrontation by the authorities that endorsed ensured restrictions and continued incarceration. To elucidate further, the acts by which patients show their rejection of the institution, including refusal and lack of cooperation, are construed by the asylum authorities as a symptomology of mental illness that serves as evidence that the patient belongs in the asylum. In other words, institutionalisation out-manoeuvres the patient by reading disaffiliation as symptoms of madness (Goffman 1971, 269; see also Foucault 2006, 297-333). 
Apart from outright refusal, there are also images in the casebooks of 'everyday forms of resistance' (Scott 1985). These are not dramatic confrontations of refusal but pertain to the ordinary weapons of relatively powerless groups to connote their lack of full compliance to authorities or dissatisfaction with instructions (Scott 1985, 29). In the casebooks many of the photographs suggest that the patients connoted disapproval and disdain by the means of their facial expressions and body language. It is precisely these elements that constituted the patients' 'everyday forms of resistance', a way to convey contempt for the institution but to avoid a direct confrontation with the asylum authorities. As a result, the viewer sees charged images of individuals asserting their scorn for the establishment but without being met by tactical interventions from the asylum.

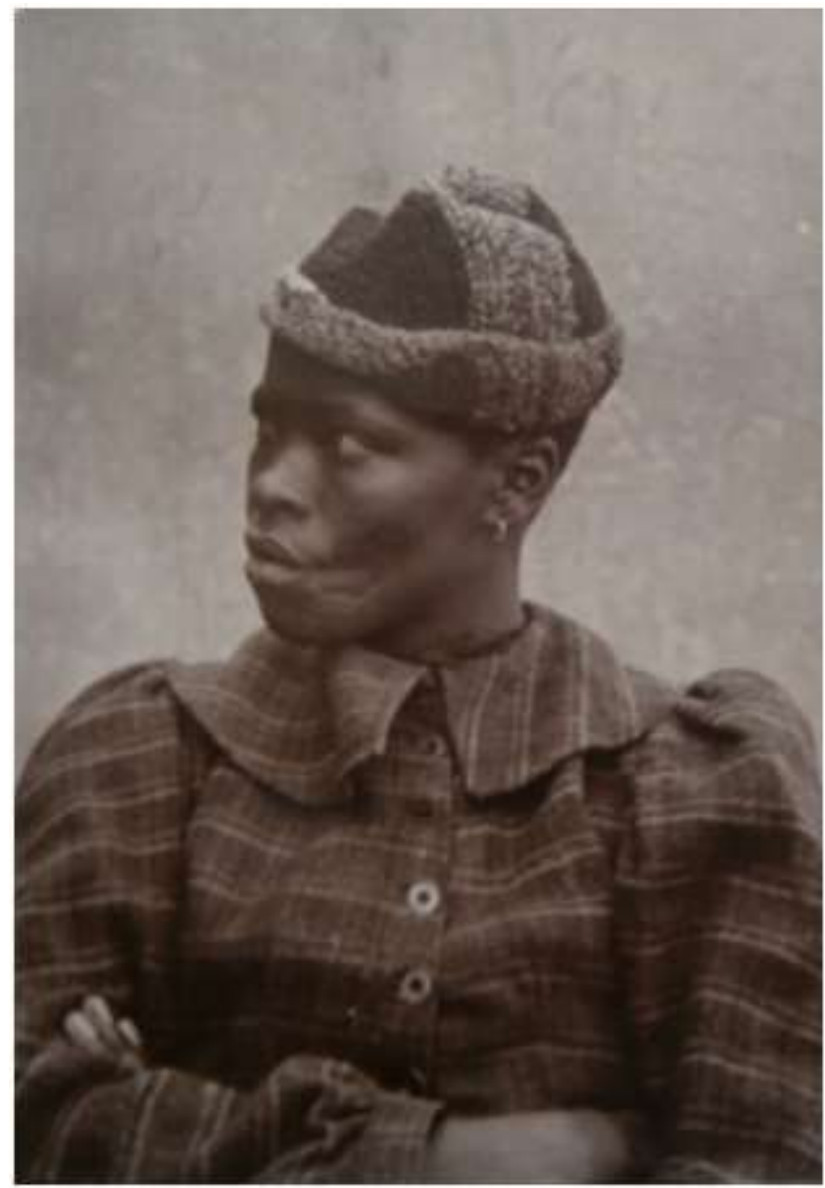

Figure 7. Patient E.T. Reproduced by permission of the Western Cape Archives and Record Service, reference number: HGM 18. 
An act of 'everyday forms of resistance' is identifiable in Figure 7 in which the female patient looks away from the camera. Instead of complying with the norm of casebook photographs - a full frontal view where the face of the subject looks directly into the camera with an invariably grave and vacant expression - the patient looks away to the side with her arms firmly crossed. She refuses the assent of the clinical and/or colonial gaze and thereby resists being treated solely as a clinical type of insanity or a specimen of colonial curiosity. In so doing, she forces the viewer to acknowledge her not as a depersonalised product of psychiatric discourse but to register her as an active subject instituting a personalised form of defiance.

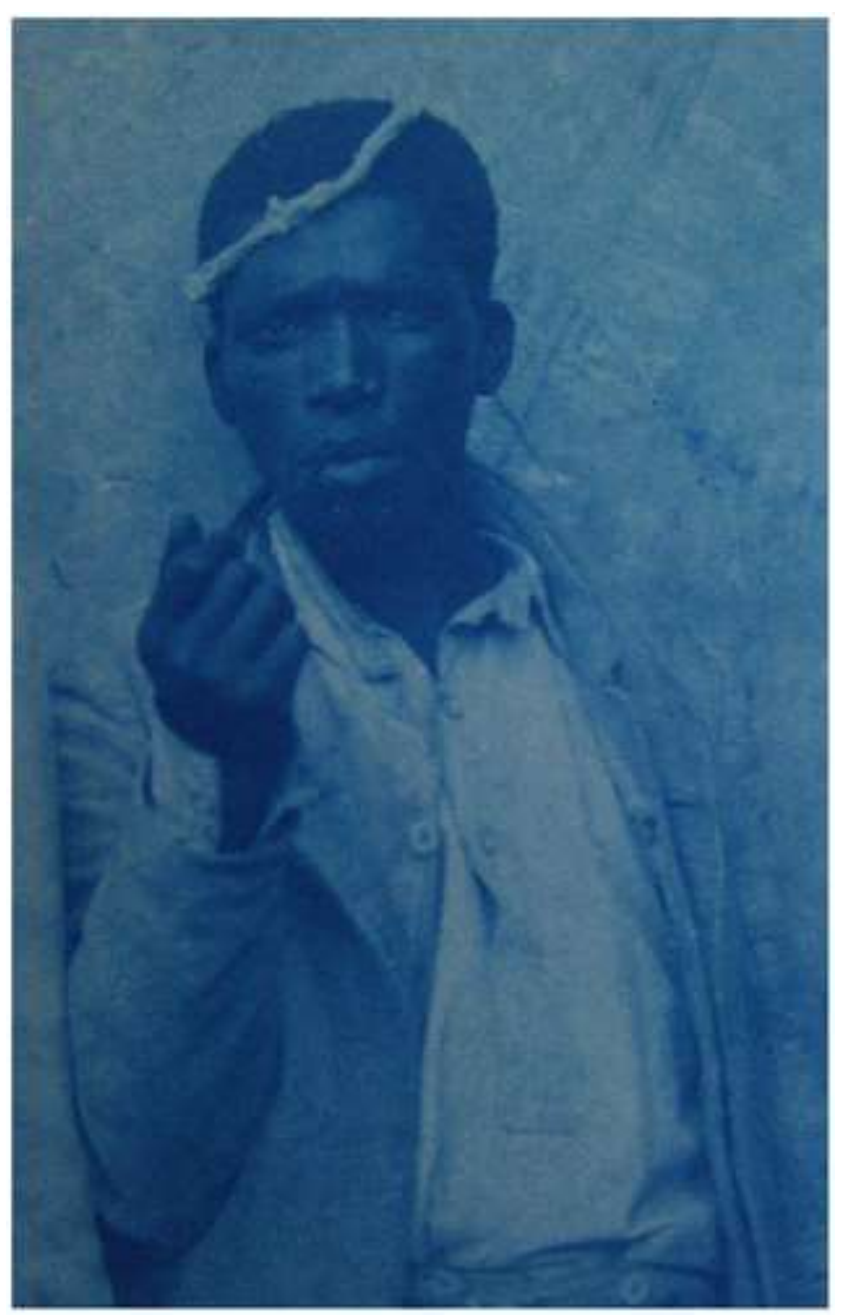

Figure 8. Patient M.L. Reproduced by permission of the Western Cape Archives and Record Service, reference number: HGM 5. 
The existence of a returned gaze (Bal 1991, 43) is evident in Figure 8. The patient stares back at the viewer with a confrontational gaze that does not express complicity to the asylum regime. This reading is further aided by the patient constructing not only a pose but also a sense of self-identity through a self-fashioned makeshift 'head-band'. To elucidate further, Goffman (1971, 28-29) argues that wearing a uniform is a form of degradation as it prevents the individual from presenting their usual image of themselves to others. In the process, one key basis of self-identification for the patient is ignored in favour of shaping and coding the patient into an "...object that can be fed into the administrative machinery of the establishment, to be worked on smoothly by routine operations" (Goffman 1971, 26). Thus, even with the mortification suffered from wearing a uniform, the patient is able to establish and articulate a selfidentity of his own choosing. Moreover, he has an object in his mouth which is reminiscent of a pipe and allows one to interpret his pose and demeanour as that of a pipe-smoking gentleman. Rather than adopting a victimised and lowly pose fitting that of an embattled patient, he holds his body in a commanding pose; a pose that might be mimed from the psychiatrist-in-charge of his case. If this were the case or intent of the patient, could it be read as a self-conscious act by the patient to present the psychiatrist with a reflection of his own image? In this sense, did the patient master the courage not only to return the camera's gaze (du Preez 2008, 435) but to also master the art of miming the coloniser?

The above reading has hinted that performance for the camera might be an important consideration in the analysis of casebook photographs. As previously outlined, studies (see Hamlett and Hoskins 2013; Sidlauskas 2013) have shown how patients have fashioned, posed, enacted and constructed their representation in asylum photographs as a significant assertion of subjectivity (Sidlauskas 2013, 2). Accordingly, 
could it be plausible to believe that some colonial subjects adopted a certain demeanour or pose in order to receive discharge from the asylum? That they posed and performed in ways indicative of 'health', 'sanity' and were at all times cooperative with colonial authority?

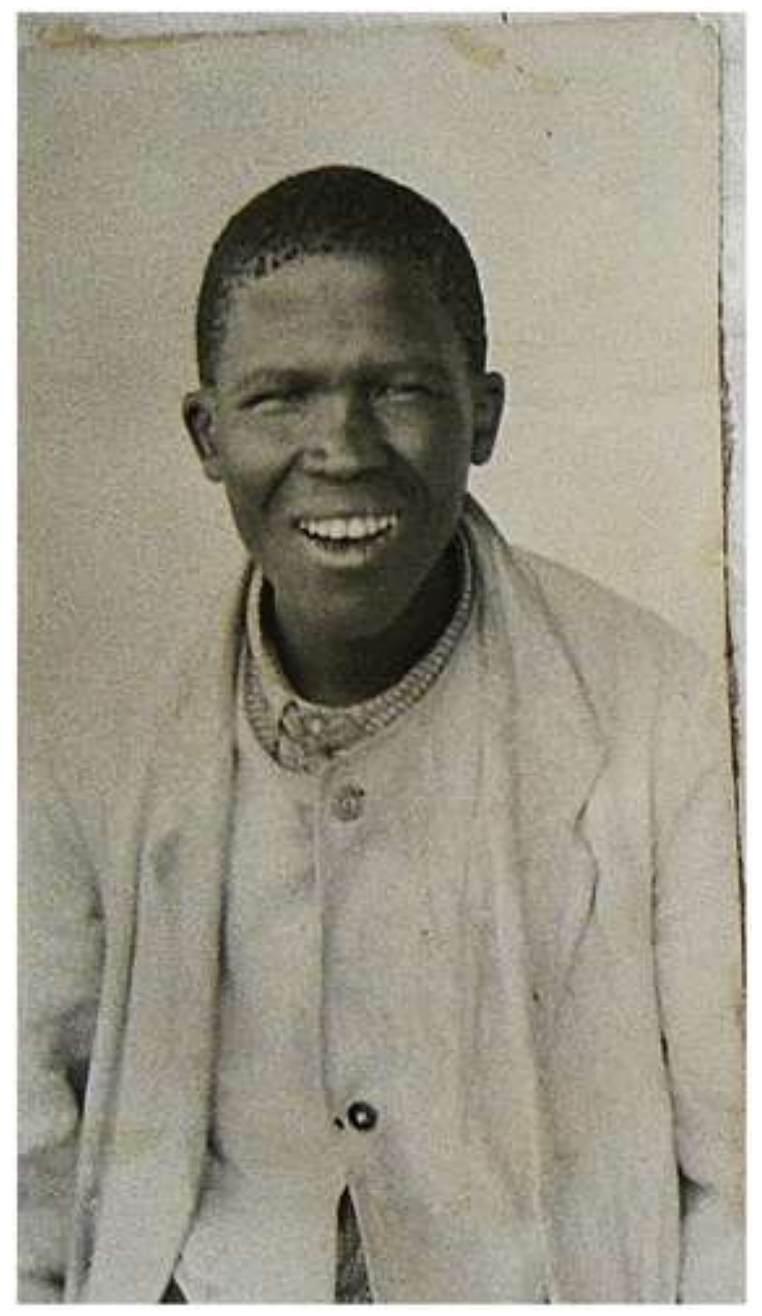

Figure 9. Patient B.K. Reproduced by permission of the Western Cape Archives and Record Service, reference number: HGM 3.

In order to offer a tentative speculation, I will refer to Figure 9. The figure is set apart from most casebook photographs by disarming the viewer with a contented or pleased expression. For Rydell (1998, 59-60) such an expression operates on multiple levels. It could negate the accounts of abuse and mortification at the asylum. It may also 
reinforce the colonial myth that blacks were similar to childlike human beings (Rydell 1998, 59-60). Or could it be a strategic public performance enacted by the patient to embody docility in order to achieve discharge from the asylum. In this sense, the patient may be appropriating the performances of submission or colonial stereotypes in order to achieve his own ends (Scott 1990, 1-34).

The performance by the patient is worked into the casebook entries by the doctors narrating his increasing improvement based on his useful work in the kitchen and his intelligent appearance. The last entry made in the casebook prior to his discharge as 'recovered' - in a period of only ten months of institutionalisation - was "He has continued to improve during the last month and is now quite fit for discharge. He is cheerful, works well, and is intelligent in conversation" (HGM 3). Such a performance of compliance to the wishes of the doctors while indicating conformity to institutional rules is widely cited in international studies of asylum patients as an effective strategy to imply recovery to consequently lead to their discharge (Digby 1985, 196). Moreover, by employing such a strategy, the patient shows an intrinsic awareness of the asylum's operations: patients who act in manageable and respectful ways are not only rewarded with better living conditions but are also viewed as indicators of recovery (Goffman 1971, 270).

One of the pitfalls that the patient's view of mental illness risks, according to Porter $(1985,182)$, is “...turning the idylls of the sick into one long bellyache, a primal scream against the atrocities perpetrated by Nature and by social oppression; neither must we sentimentalize victimhood as if suffering were beautiful." In cognisance of this cautionary remark, the various readings provided - of resistance, fear and performance - still fall short of an attempt to interpret the patients' views of the asylum. One missing 
element is how the patients developed a meaningful life of their own while within the total institution of the asylum (Goffman 1971, 7).

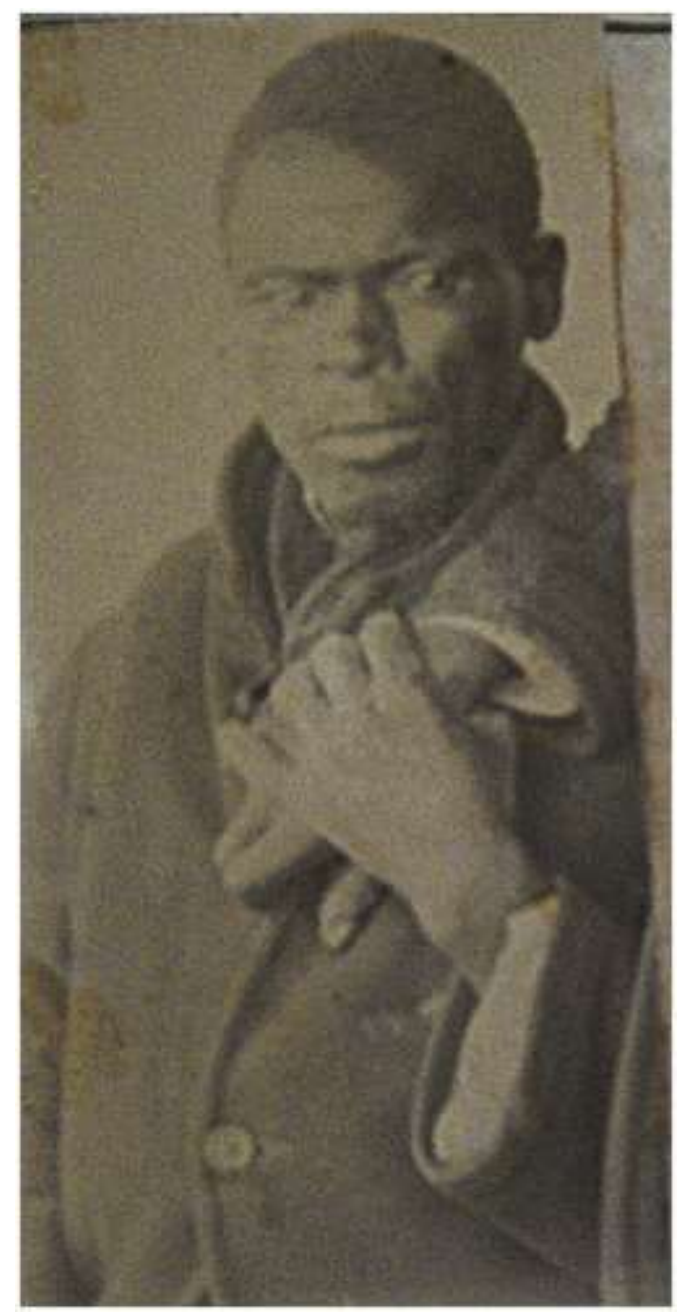

Figure 10. Patient J.B. Reproduced by permission of the Western Cape Archives and Record Service, reference number: HGM 3.

One photograph that I believe indicates such an existence is Figure 10. Unlike the previous photographs discussed, the subject does not refuse, resist or express disdain. The photograph may even be a rather banal image of a patient in uniform dress captured full-frontally before the camera. Yet, the element that disturbs and pierces me, the punctum, is the hand of another patient - from outside the frame of the photograph placed on the chest of the subject. The subject warmly embraces the other patient's hand. It is this act of reciprocation that is poignant to me and that I read as a symbol of 
solidarity, camaraderie and supportive relations existing between the patients. Goffman $(1971,7 ; 244)$ affirms that in every group of people, even patients, bonds of solidarity exist in the group. Thus there exists a potential to investigate bond formation or even friendship between patients as an important element in accounting for the patient's view of the asylum. The interesting possibility lies in exploring whether mutual regard and aid amongst patients provided important ways to build support networks that mitigate the debasements and sufferings of institutionalisation (Reaume 2000, 99).

From the above discussion, it has become apparent that while the casebook photographs were deployed by the asylum as a means of identification they also recorded patients refusing the clinical gaze, of patients expressing disdain for the institution, of mimicry and performance. Additionally, the photographs provide a glimpse of patient relations and human camaraderie that is largely muted in official records. Thus the photographs provide an attempt at articulating a patient's view of the asylum. Although such an attempt remains precarious, it nevertheless undermines the public image of the asylum as constituted by docile black bodies.

\section{Conclusion}

The central concern in this essay has been to challenge the public image of black patients as docile and passive before the asylum's regimen. The importance of such an approach in countering the public image is best articulated by Sekula (1986). For Sekula $(1986,64)$, a significant part of the testimony of the oppressed and exploited takes the ambiguous form of visuals. It is our role as intellectuals to "... help prevent the cancellation of that testimony by more authoritative and official texts" (Sekula 1986, 64). Accordingly, the casebook photographs problematize the simplistic narrative of the public image and provide evidence of the patients' refusal, resistance and disdain for the 
institution. Thus, the casebook photographs are compelling evidence to reconsider the official image of the asylum as a visual fiction. Moreover, the casebook photographs provide one means to enable us to envision the patient's view of the asylum. What emerges is the visual narratives of patients who possibly performed markers of health to receive discharge from the asylum. But what also comes into view are new meanings of an institutionalised life in which camaraderie amongst the patients may have provided encouragement, aid, and defence, against the asylum's regimen and acts of mortification.

\section{Acknowledgements}

The photographs are reproduced with permission from the Western Cape Archives and Records Service.

\section{Notes}

1. Although the photographs were commissioned and disseminated by Greenlees, there is no indication of who the actual photographer was.

2. The term 'patient' can be regarded as problematic as it pertains to a narrow medical model that premises that the individual receiving psychiatric services is indeed mentally ill. Additionally, the term is also negatively connoted with paternalism and disability. However, the alternatives to 'patient' - namely: 'client', 'consumer', and 'survivor' prove to be just as contentious (Sharma, Whitney, Kazarian and Manchanda 2000). Although I will use the term 'patient', I will indicate how my use of it departs from traditional definitions. For the purposes of this article, 'patient' refers to individual human beings that are neither defined by diagnostic categories nor are they anonymous inmates of the asylum. Rather 'patients', as reformulated by Reaume $(2000,99)$, are individuals who are active in formulating ways to cope with institutionalization, are capable of close personal friendships and may express resistance to power.

3. The influence of moral therapy is marked from the last decades of the eighteenth century through to the nineteenth century (Curtis 2004, 197; Parle 2007, 45). Yet, its central tenets remained a part of the design of psychiatric institutions until the midtwentieth century (Hickman 2007). Thereafter, the basic elements of moral therapy became adjuncts to mental health treatment under new terminologies such as 
occupational therapy and milieu therapy (Borthwick et al 2001). To elucidate but one new terminology further, milieu therapy is derived from the basic principles of moral therapy and is acknowledged as pertinent treatment in contemporary mental health care. For example, in an article that outlines the recommendations for a South African psychiatric hospital to adopt in order to offer quality mental care to patients, the author states that "Optimal use should be made of the beautiful grounds of the hospital. A walking trail should be developed and used for exercise and milieu therapy" (Mkize 2007, 141).

4. In the Cape Colony the position of Inspector of Asylums was created for the purpose of implementing moral therapy at the Cape. Dr William Dodds was appointed in this role from 1889-1913 (Swartz 1995b).

5. Photography was not only aligned to physiognomy but was a central means for the development of other pseudo-scientific practices including phrenology and social Darwinist race theories (Popple 2005, 95).

6. For example, please see the photograph titled 'The male corridor for blacks, Fort England Asylum, Grahamstown after renovation in 1894' (Reference number: A.G. 401, Western Cape Archives and Records Service).

7. For example, please see the photograph titled 'The kitchen, Fort England Asylum, Grahamstown, 1890' (Reference number: A.G. 398, Western Cape Archives and Records Service).

8. It is imperative though to recognise that there was no 'colonial great confinement' and that colonial psychiatry never engaged in a large-scale incarceration for the purposes of direct social control (Vaughan 2007, 2-3). On a structural level this is attributed to the fact that the colonies suffered a scarcity of asylums and available beds (Deacon 2003, 27; Swartz 2009, 72). Thus, the majority of admissions were limited to black men who were neither docile nor domesticated and hence were seen to be a menace to colonial work regimes and social roles (Deacon 2003, 27; Swartz 2009, 72; Vaughan 1991, 125). Accordingly, it was the black insane that was living near or working with white communities that came to the attention of the colonial authorities - the black insane living in isolated rural communities were not a major concern (Deacon 2003, 52).

9. The docility of the black patient as a marker of 'cure' is not just consigned to the nineteenth century. For Fanon $(1967,201)$, colonialism in the twentieth century is represented as a success when the "indocile" nature of the natives had been tamed. In this formation, to 'cure' a psychiatric patient under colonialism is to seek "...to make him thoroughly a part of a social background of the colonial type" (Fanon 1967, 200). 


\section{References}

Amirault, C. 1993. "Posing the Subject of Early Medical Photography." Discourse 16 (2): 51-76.

Andrews, J. 2007. "The (un)dress of the mad poor in England, c. 1650-1850. Part One." History of Psychiatry 18 (01): 5-24.

Bal, M. 1991. "The politics of citation." Diacritics 21 (1): 25-45.

Barthes, R. 2000 (1981). Camera Lucida. Translated by R. Howard. London: Vintage.

Berkenkotter, C. 2008. Patient tales: case histories and the uses of narrative in psychiatry. Columbia: University of South Carolina Press.

Bressey, C. 2011. "The city of others: photographs from the City of London Asylum Archive." Interdisciplinary Studies in the Long Nineteenth Century 19 (13).

Buda, O. 2010. "The face of madness in Romania: the origin of psychiatric photography in Eastern Europe." History of Psychiatry 21 (3): 278-293.

Bogdan, R., and A. Marshall. 1997. "Views of the Asylum: Picture postcard depictions of institutions for people with mental disorders in the early 20th century." Visual Sociology 12: (1): 4-27.

Borthwick, A., C. Holman, D. Kennard, M. Mcfetridge, K. Messruther and J. Wilkes. 2001. "The relevance of moral treatment to contemporary mental health care." Journal of Mental Health 10(4):427-439.

Burrows, E. H. 1958. A history of medicine in South Africa: up to the end of the nineteenth century. Cape Town: AA Balkema.

CCP 1/2/1/43: Report on the Graham's Town Lunatic Asylum for year 1879. Cape of Good Hope Official Publications

CCP1/2/1/46: Report on the Graham's Town Lunatic Asylum for year 1880. Cape of Good Hope Official Publications

CCP 1/2/1/50: Report on the Graham's Town Lunatic Asylum for year 1881. Cape of Good Hope Official Publications

CCP 1/2/1/55: Report on the Graham's Town Lunatic Asylum for year 1882. Cape of Good Hope Official Publications

CCP 1/2/1/71: Reports on the Medical Committee, the vaccination Surgeon and the Government and Public Hospitals and Asylums for 1887. Cape of Good Hope Official Publications

CCP 1/2/1/73: Reports on the Medical Committee, the vaccination Surgeon and the Government and Public Hospitals and Asylums for 1888. Cape of Good Hope Official Publications

CCP 1/2/1/77: Reports on the Medical Committee, the vaccination Surgeon and the Government and Public Hospitals and Asylums for 1889. Cape of Good Hope Official Publications

CCP 1/2/1/79: Reports on the Medical Committee, the vaccination Surgeon and the Government and Public Hospitals and Asylums for 1890. Cape of Good Hope Official Publications

CCP 1/2/1/82: Reports on the Medical Committee, the vaccination Surgeon and the Government and Public Hospitals and Asylums for 1891. Cape of Good Hope Official Publications

CCP 1/2/1/84: Reports on the Government and Public Hospitals and Asylums, and Report on the Inspector of Asylums for 1892. Cape of Good Hope Official Publications

CCP 1/2/1/89: Reports on the Government and Public Hospitals and Asylums, and Report on the Inspector of Asylums for 1893. Cape of Good Hope Official Publications 
CCP 1/2/1/92: Reports on the Government and Public Hospitals and Asylums, and Report on the Inspector of Asylums for 1894. Cape of Good Hope Official Publications

CCP 1/2/1/108: Reports on the Government and Aided Hospitals and Asylums and Report of the Inspector of Asylums for 1898. Cape of Good Hope Official Publications

CCP 1/2/1/112: Reports on the Government and Aided Hospitals and Asylums and Report of the Inspector of Asylums for 1899. Cape of Good Hope Official Publications

CCP 1/2/1/115: Reports on the Government and Aided Hospitals and Asylums and Report of the Inspector of Asylums for 1900. Cape of Good Hope Official Publications

Condrau, F. 2007. "The patient's view meets the clinical gaze." Social History of Medicine 20 (3): 525-540.

Cross, S. 2004. "Visualising madness: mental illness and public representation." Television New Media 5 (3): 197-216.

Cross, S. 2010. Mediating madness: mental distress and cultural representation. Houndmills: Palgrave Macmillan.

Curtis, S. 2004. Health and inequality: geographical perspectives. London: SAGE.

Davis, J. E. 2006. "Suffering, pharmaceutical advertising, and the face of mental illness." The Hedgehog Review. 8 (3): 62-77.

Deacon, H. J. 1996. "Madness, race and moral treatment: Robben Island Lunatic Asylum, Cape Colony, 1846-1890.” History of Psychiatry 7: 287-297.

Deacon, H. 1999. "Racial categories and psychiatry in Africa: the asylum on Robben Island in the nineteenth century." In Race, science and medicine, 1700-1960, edited by W. Ernst and B. Harris, 101-122. London: Routledge.

Deacon, H. 2003. "Insanity, institutions and society: the case of the Robben Island Lunatic Asylum, 1846-1910." In The confinement of the insane: international perspectives, 1800-1965, edited by R. Porter and D. Wright, 20-53. Cambridge: Cambridge University Press.

Diamond, H. W. 1976 (1856). "On the application of photography to the physiognomic and mental phenomena of insanity." In The face of madness, edited by S. L. Gilman, 17-24, New York: Brunner.

Didi-Huberman, G. 2003 (1982). Invention of hysteria: Charcot and the photographic iconography of the Salpêtrière. Translated by A. Hartz. Cambridge: MIT Press.

Digby, A. 1985. Madness, morality and medicine. A study of the York Retreat, 17961914. Cambridge: Cambridge University Press.

Du Plessis, R. 2012. "The influence of moral therapy on the landscape design of lunatic asylums built in the nineteenth century." De Arte 86: 21-38.

Du Preez, A. 2008. "Through the Empire's eyes: engaging the gaze." Religion \& Theology 15: 427-446.

Fanon, F. 1967 (1961). The wretched of the earth. Translated by C. Farrington. London: Penguin.

Foucault, M. 1979 (1976). The will to knowledge: the history of sexuality, volume 1. Translated by R. Hurley. London: Penguin.

Foucault, M. 2006. Psychiatric power: Lectures at the College de France, 1973-74. Translated by G. Burchell. Houndmills: Palgrave Macmillan.

Gewurtz, M. S. 2006. "Looking for Jean Dow: narratives of women and missionary medicine in modern China." In Figuring it out: science, gender, and visual 
culture. Edited by A. B. Shteir and B. Lightman, 267-288. Hanover: Dartmouth College Press.

Gilman, S. L., ed. 1976. The face of madness: Hugh W. Diamond and the origin of psychiatric photography. New York: Brunner / Mazel.

Gilman, S. L. 1988. Disease and representation: images of illness from madness to AIDS. Ithaca \& London: Cornell University Press.

Gilman, S. L. 1996 (1982). Seeing the insane. London: University of Nebraska Press.

Godbey, E. 2000. "Picture me sane: photography and the magic lantern in a nineteenthcentury asylum." American Studies 41 (1): 31-69.

Goffman, E. 1973 (1961). Asylums. Essays on the social situation of mental patients and other inmates. Harmondsworth: Penguin.

Greenlees, T. D. 1895. "Insanity among the natives of South Africa." Journal of Mental Science 41: 228-234.

Greenlees, TD. 1892. The nursing and management of the insane. A lecture delivered to the nursing staff of the city of London Asylum and (with certain alterations) to the nursing staff of Grahamstown Asylum, Cape Colony. Grahamstown Asylum: Asylum Press.

Grob, G. N. 1985. "The transformation of the mental hospital in the United States." American Behavioral Scientist 28(5):639-654.

Guyatt, M. 2004. “A semblance of home: mental asylum interiors, 1880-1914.” In Interior design and identity, edited by S. McKellar and P. Sparke, 4871.Manchester: Manchester University Press.

Hamlett, J., and L. Hoskins. 2013. "Comfort in Small Things? Clothing, control and agency in county lunatic asylums in nineteenth- and early twentieth-century England." Journal of Victorian Culture, DOI:10.1080/13555502.2012.744241

Hawkins, K. 1991. "The therapeutic landscape: nature, architecture, and mind in nineteenth-century America." Ph.D. thesis. Rochester: University of Rochester.

Hickman, C. 2007. "Therapeutic landscapes: the design and use of nineteenth-century lunatic asylum grounds." Accessed 02 June 2011. http://www.parksandgardens.ac.uk/274/explore-31/feature-articles151/therapeutic-landscapes-the-design-and-use-of-nineteenthcentury-lunaticasylum-grounds-546.html

HGM: "Grahamstown Lunatic Asylum casebooks." Volumes 3, 4, 5, 17, 18, 20.Western Cape Archives and Record Service

Houston, R. A. 2003. "The Face of Madness in Eighteenth-and Early NineteenthCentury Scotland." Eighteenth-Century Life 27 (2): 49-66.

Jackson, L. A. 2005. Surfacing up: psychiatry and social order in colonial Zimbabwe, 1908-1968. Ithaca and London: Cornell University Press.

Jones, T.F. 2012. Psychiatry, mental institutions, and the mad in Apartheid South Africa. London: Routledge.

Lalu, P. 2009. The deaths of Hintsa: postapartheid South Africa and the shape of recurring pasts. Cape Town: HSRC Press.

Logan P. M. 2008. "Imitations of insanity and Victorian medical aesthetics." Romanticism and Victorianism on the Net $(\mathrm{RaVoN})$ (49). Accessed 13 May 2013. http://www.erudit.org/revue/ravon/2008/v/n49/017855ar.html.

Manzoli, F. 2004. "Images of madness. The end of mental hospitals illustrated through photographs." Journal of Science Communication 3 (2): 2-7.

Marks, S. 1999. "'Every facility that modern science and enlightened humanity have devised': race and progress in a colonial hospital, Valkenberg Mental Asylum, Cape Colony, 1894-1910." In Insanity, institutions and society, 1800-1914: a 
social history of madness in comparative perspective, edited by J. Melling and B. Forsythe, 268-291. London: Routledge.

McClintock, A. 2001. Double crossings: madness, sexuality and imperialism. Vancouver: Ronsdale Press.

Mkize, L. 2007. "Human rights abuses at a psychiatric hospital in KwaZulu-Natal." South African Journal of Psychiatry 13(4): 137-142.

Parle, J. 2007. States of mind: searching for mental health in Natal and Zululand, 18681918. Scottsville: University of KwaZulu-Natal Press.

Plug, C., and J. L. Roos. 1992. "Weskoppies Hospital, founded 1892 - the early years." South African Medical Journal 81: 218-221.

Popple, S. 2005. "Photography, crime and social control." Early Popular Visual Culture 3 (1): 95-106.

Reaume, G. 2000. Remembrance of patients past: patient life at the Toronto Hospital for the Insane, 1870-1940. Don Mills: Oxford University Press.

Reviews and notices. 1894. South African Medical Journal July: 82.

Porter, R. 1985. "The Patient's View: Doing Medical History from below." Theory and Society 14 (2): 175-198.

Porter, R. 2001. Bodies politic: disease, death and doctors in Britain, 1650-1900. Ithaca: Cornell University Press.

Rydell, R. W. 1998. "Souvenirs of imperialism." In Delivering views: distant cultures in early postcards, edited by C. M. Geary and V-L. Webb, 47-63. Washington \& London: Smithsonian Institution Press.

Sachs, N. A. 1999. "Psychiatric hospitals." In Healing gardens: therapeutic benefits and design recommendations, edited by C. C. Marcus and M. Barnes, 235-322. New York: John Wiley \& Sons.

Scott, J. C. 1990. Domination and the arts of resistance: hidden transcripts. New Haven \& London: Yale University Press.

Scott, J. C. 1985. Weapons of the weak: everyday forms of resistance. New Haven and London: Yale University Press.

Sekula, A. 1986. "The body and the archive." October 39: 3-64.

Sidlauskas, S. 2013. "Inventing the medical portrait: photography at the 'Benevolent Asylum' of Holloway, c. 1885-1889.” Medical Humanities 1-10. doi:10.1136/medhum-2012-010280.

Sharma, V. D., S. S. Whitney, R. Kazarian, and R. Manchanda. 2000. "Preferred terms for users of mental health services among service providers and recipients." Psychiatric Services 51(2): 203-209.

Showalter, E. 1987. The female malady: women, madness and English culture, 18301980. London: Virago.

Sontag, S. 1973. On photography. New York: Picador.

Sutton, S. B. 1986. Crossroads in psychiatry: a history of the McLean Hospital. Washington: American Psychiatric Press.

Swanson, F. 1994. "Colonial madness: the construction of gender in the Grahamstown Lunatic Asylum, 1875-1905." Honours thesis. Cape Town: University of Cape Town.

Swanson, F. 2001. "“Of unsound mind': a history of three Eastern Cape mental institutions, 1875-1910." M. A. thesis. Cape Town: University of Cape Town.

Swartz, S. 1995a. "Colonizing the insane: causes of insanity in the Cape, 1891-1920." History of the Human Sciences 8 (4): 39-57.

Swartz, S. 1995b. "The black insane in the Cape, 1891-1920." Journal of Southern African Studies 21 (3):sp. 
Swartz, S. 1996. "Colonialism and the production of psychiatric knowledge in the Cape, 1891-1920." D. Phil thesis. Cape Town: University of Cape Town.

Swartz, S. 1999. "Lost lives: gender, history and mental illness in the Cape, 18911910". Feminism \& Psychology 9 (2): 152-158.

Swartz, S. 2005. "Can the clinical subject speak?: some thoughts on subaltern psychology." Theory Psychology, 15 (4): 505-525.

Swartz, S. 2008. "Colonial lunatic asylum archives: challenges to historiography." Kronos 34 (1): 285-302.

Swartz, S. 2009. "Madness and method: approaches to the history of mental illness." Psychology in Society 37: 70-74.

The Fort England Mirror. 1893. The British Journal of Psychiatry 39: 264-265.

Topp, L. 2007. "The modern mental hospital in the late nineteenth-century Germany and Austria: psychiatric space and images of freedom and control." In Madness, architecture and the built environment: psychiatric spaces in historical context, edited by L. Topp, J. E. Moran and J. Andrews, 241-262. London: Routledge.

Vaughan, M. 1991. Curing their ills: colonial power and African illness. Oxford: Polity Press.

Vaughan, M. 2007. "Introduction." In Psychiatry and empire, edited by S. Mahone and M. Vaughan, 1-16. Houndmills: Palgrave Macmillan.

Whittaker, E. 2009. "Photographing race: the discourse and performance of tourist stereotypes." In The framed world: tourism, tourists and photography, edited by M. Robinson and D. Picard, 117-137. Farnham: Ashgate.

Wynter, R. 2011. “'Good in all respects': appearance and dress at Staffordshire County Lunatic Asylum, 1818-54." History of Psychiatry, 22(1): 40-57.

Yanni, C. 2003. "The Linear Plan for insane asylums in the United States before 1866." Journal of the Society of Architectural Historians, 62 (1): 24-49. 